\title{
Design, Modeling, and CFD Analysis of a Micro Hydro Pelton Turbine Runner: For the Case of Selected Site in Ethiopia
}

\author{
Tilahun Nigussie, ${ }^{1}$ Abraham Engeda, ${ }^{2}$ and Edessa Dribssa ${ }^{1}$ \\ ${ }^{1}$ School of Mechanical and Industrial Engineering, Addis Ababa Institute of Technology, Addis Ababa, Ethiopia \\ ${ }^{2}$ Department of Mechanical Engineering, Michigan State University, East Lansing, USA \\ Correspondence should be addressed to Tilahun Nigussie; tilahun.nigussie@aait.edu.et
}

Received 4 June 2017; Revised 17 August 2017; Accepted 29 August 2017; Published 12 October 2017

Academic Editor: Rafat Al-Waked

Copyright ( 2017 Tilahun Nigussie et al. This is an open access article distributed under the Creative Commons Attribution License, which permits unrestricted use, distribution, and reproduction in any medium, provided the original work is properly cited.

\begin{abstract}
This paper addresses the design, modeling, and performance analysis of a Pelton turbine using CFD for one of the selected micro hydro potential sites in Ethiopia to meet the requirements of the energy demands. The site has a net head of $47.5 \mathrm{~m}$ and flow rate of $0.14 \mathrm{~m}^{3} / \mathrm{s}$. The design process starts with the design of initial dimensions for the runner based on different literatures and directed towards the modeling of bucket using CATIA V5. The performance of the runner has been analyzed in ANSYS CFX (CFD) under given loading conditions of the turbine. Consequently, the present study has also the ambition to reduce the size of the runner to have a cost effective runner design. The case study described in this paper provides an example of how the size of turbine can affect the efficiency of the turbine. These were discussed in detail which helps in understanding of the underlying fluid dynamic design problem as an aid for improving the efficiency and lowering the manufacturing cost for future study. The result showed that the model is highly dependent on the size and this was verified and discussed properly using flow visualization of the computed flow field and published result.
\end{abstract}

\section{Introduction}

Despite the fact that many rural communities have good access to plenty of water resources, the most serious problem faced by a country like Ethiopia is that of rural electrification. One of the most important and achievable methods to produce electricity is to introduce a standalone electric power generation, using renewable resources. Rural Electrification Fund (REF), which is operating under the Ministry of Water, Irrigation and Energy (MWIE), is working to control the energy crisis in the country [1-3]. In its effort, it has identified some potential micro hydro sites in the country. This potential for small-scale hydro power is estimated to be $10 \%$ of the total potential $(1,500-3,000 \mathrm{MW})[3,4]$. So far, out of the total potentials for micro hydro power (MHPs) in the country (over $1000 \mathrm{MW}$ ) only a minute portion of it (less than $1 \%$ ) is developed [4]. If these water resources were properly harnessed, it will help Ethiopia to meet its power demand and maintain her economic growth for the next decade. Due to the existence of these numerous sites in Ethiopia, suitable for micro hydro turbine installations, the need for development of micro hydro turbines using locally available materials and with local manufacturing capability has been identified for those sites which have been evaluated and proved to be viable, the aim being to cut the equipment cost which is imported from various countries from Europe and Asia. As a result, future of micro hydro developments in the country would need a manufacturer to provide turbines and parts with new design.

Figure 1 shows some MHP areas. These areas are mainly in the Western and South-Western part of the country and they are characterized by high mean annual rainfall ranging from $300 \mathrm{~mm}$ to over $900 \mathrm{~mm}$. For many of these sites, a Pelton turbine is the only option. This is due to higher mountains providing higher heads and seasonal variation in flow rates appropriate for the choice of Pelton turbines for hydro power projects in the country [4-6].

Depending on water flow and design, Pelton wheels operate best with heads from 15 meters to 1,800 meters, although there is no theoretical limit. In this turbine, water 

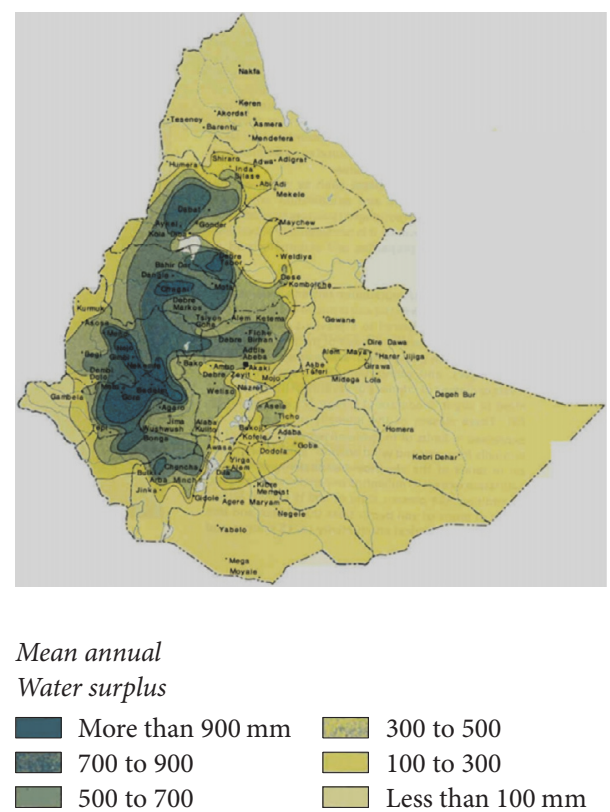

FIGURE 1: Distribution of MHP potential sites in Ethiopia [4].

is brought down through the penstock pipe to a nozzle, and it comes out into the turbine casing. The jet is then directed at a wheel, or runner, which has a number of buckets around its edge. The force of the jet on this wheel makes it turn and gives the output power [7-9]. However, investigation reveals that there is no company or institution engaged in supplying this micro Pelton turbine locally in the country. As a result, the necessity and the possibilities to design and manufacture Pelton turbines locally are increasing. More often the material and the skilled labour as well as technical staff are available but what is missing is the information and knows-how $[4,6]$.

More precisely, in the new context where harvesting small hydro potentials can become economically viable, there is also a need to provide solutions to reduce the design cycle time and cost for Pelton runners. It is known that, with increasing demand, the performance analysis of turbine such as efficiency and dynamic behavior is also an important aspect to analyze its suitability under different operating conditions [7]. Additionally, it is used by the turbine producer to guarantee the hydraulic performance of a turbine to the customer. However, it is known that design of Pelton turbine is mainly conducted from know-how and extensive experimental testing, which provide an empirical understanding of factors that are important to turbine design. But, in today's highly competitive market of turbine, the performance is often difficult to determine in the short term with this traditional practice. Therefore, the incorporation of computational fluid dynamics (CFD) in the design of micro hydro turbines appears to be necessary in order to improve their efficiency and cost-effectiveness beyond the traditional design practices [7, 10-12].

The main topic of investigations by the CFD method has focused on the interactions between the jet and the rotating buckets as well as the relative flows within the buckets. These are flows that are so far not easily accessible by experimental measurements [11]. CFD simulations are therefore likely considered as an available way for investigating complex flows in Pelton turbines, provided that they are reliable and able to reveal the possibility of improving the system efficiency and reducing the manufacturing cost. In addition, CFD provide deeper understanding of the flow mechanisms that govern performance. The most detailed CFD analysis of rotating Pelton turbine was done by Perrig et al. $[13,14]$ by considering five buckets and the computed results were compared with experimental results at best efficiency point (BEP).

As explained by Zhang [7] in Pelton turbine book, hydraulic design of a Pelton turbine, the related practical experiences have thus always played a major role besides applying general design rules. Even the optimum bucket number and the size of a Pelton wheel, for instance, were determined only by experience or model tests without relying on any hydro mechanical background. The main reasons for this were the complex flow conditions in both the high-speed jet and the unsteady interaction between the high-speed jet and the rotating Pelton buckets [7, 11]. But nowadays, the largest amount of publications on modeling of Pelton turbines uses commercial code ANSYS CFX [7, 10, 14]. The capability of solving complex impulse turbine related problems that include multiphase flow with free surfaces has been demonstrated by a number of studies and is becoming increasingly significant [10-18]. However, large computational cost of the simulations is also the main factor why there is a lack of publications on CFD usage for Pelton turbines [11]. As a result, various authors made different simplifying assumptions in order to reduce this cost as much as possible and make Pelton simulation for performance predictions possible. Most CFD simulations reviewed in the literatures were assuming symmetry in the flow as simplifying assumption and therefore they model only half of a runner or a bucket. Because of the periodic behavior assumption, the majority of simulations used also only a fraction of a runner with the number of buckets in the section modeled being 2 , 3, 5, 7, or even 10 [11]. Many authors used only 3 consecutive buckets where the torque was measured only on the bucket in the middle. This torque measured on a single middle bucket was then used to construct the torque on the runner assuming that every bucket would undergo identical loading $[10,11]$. The first bucket was required to produce the back-splashing water that impacts the middle bucket. The third bucket was required to realistically cut the jet when it is impacting the second bucket. Even though, it was shown that it is possible to model the complete runner; this could be seen as unnecessary usage of computational resources. For instance, using the same computational resources and a reduced complexity simulation with only 3 buckets would allow simulations with better discretized grids (therefore improving accuracy) or analyzing more operating points or design variations and enable the optimization of Pelton turbine (see $[11,13,14])$.

So far, few investigators have only reported diverse values of maximum efficiencies as shown in Table 1. Because of commerciality of the turbine, many of the investigators normalized their results in their publications. Most papers report that the shape of the efficiency curve is well captured, while actual differences between measured and numerically 
TABle 1: Some Pelton turbine studies and maximum efficiency levels attained.

\begin{tabular}{|c|c|c|c|c|c|}
\hline Investigators & Net head (m) & $\begin{array}{l}\text { Flow rate } \\
\left(\mathrm{m}^{3} / \mathrm{sec}\right)\end{array}$ & $\begin{array}{c}\text { Runner speed } \\
(\mathrm{rpm})\end{array}$ & $\mathrm{PCD}(\mathrm{mm})$ & $\begin{array}{l}\text { Maximum } \\
\text { efficiency, \% }\end{array}$ \\
\hline Panthee et al. [10] & 53.9 & 0.05 & 600 & 400 & 82.5 \\
\hline $\begin{array}{l}\text { Panagiotopoulos et al. } \\
\text { [19] }\end{array}$ & 100 & $135 \%$ of BEP & 1000 & 400 & 86.7 \\
\hline $\begin{array}{l}\text { Solemslie and Dahlhaug } \\
{[20]}\end{array}$ & 70 & - & - & 513 & 77.75 \\
\hline Pudasaini et al. [21] & 80.85 & 0.09218 & 600 & 490 & 87.71 \\
\hline
\end{tabular}

TABle 2: Proposed site data for MHP development [22].

\begin{tabular}{lllllc}
\hline Region & Zone & Wereda & Kebel & $\begin{array}{c}\text { River } \\
\text { name }\end{array}$ & $\begin{array}{c}\text { Head (m) } \\
(\mathrm{L} / \mathrm{s})\end{array}$ \\
\hline Oromia & W/showa & Tokikutay & $\begin{array}{c}\text { Melkey } \\
\text { Hera }\end{array}$ & Indris & $>50$ \\
\hline
\end{tabular}

predicted efficiency remain unreported. An exception is [10, 19-21], where predicted efficiency was quite close to the measurements. Fewer still go deeper into the design and performance analysis of the turbine.

Due to the natural limitations concerning publication of results concerning turbines from commercial companies, one of the goals of this research paper has been to design and simulate using a Pelton turbine and compare the obtained result with the reference from Table 1 . The results in Table 1 may have also depended on the laboratory settings and other controls of design parameters; the results still indicate room for further performance improvement. Even though this is a well-established turbine technology, there are many unanswered questions regarding design and optimization. Thus, further development is still relevant today. As a main feature, previous studies have mainly focused on experimental studies of turbine efficiency as a function of different geometrical parameters of the buckets. No paper that consists of design analysis, modeling, numerical performance analysis of rotating Pelton turbine runner, and its comparison with experimental data to reduce the size of the turbine has been published as far as we know. Therefore, a design study that takes into account the links between the size of the runner and the flow field characteristics is needed. This paper addresses this issue for one of the selected potential sites (Indris River) in Ethiopia to meet the requirements of the energy demands. The design process consists of sequential stages: parametric design of turbine, and CFD simulation with the baseline design and a smaller size of the turbine from the baseline design. The result of this study will be an input to the optimization of the runner for future study. In this way, a study was carried on Pelton turbine runner specifically designed and the result of this research was compared with that of Table 1 (published results). In the second part of this article, optimization of the geometry of this turbine, local manufacturing of the optimal geometry and testing of this turbine in the lab, and finally comparison of the results obtained will be presented. The result of this research will also ensure availability of documented procedure by contributing knowledge for designing micro hydro Pelton turbine in the country. Most importantly, a general awareness and technical understanding of successful micro hydro turbine technology will be developed and fostered at the local and regional levels so that rural electrification projects can be implemented effectively.

\section{Method and Methodology}

2.1. Problem Description. After surveying different villages in the South-West District of Ethiopia, we narrowed our choices down to one: Melkey Herra Village. It is a rural community, Keble, roughly 149 kilometers from Addis Ababa, and is well renowned for tourism. Its geographical coordinates are $08^{\circ} 51^{\prime}$ $40^{\prime \prime}$ North and $37^{\circ} 45^{\prime} 10^{\prime \prime}$ East which does not have the access to electricity. The selected water resource for hydroelectric generation is "Indris River" for the communities living in the village called "Melkey Herra" [22]. The micro hydroelectric project is a main priority to the community. Due to the recent crises of electricity in the community, it is utmost need for the utilization of micro hydropower. The data (Table 2) has been found from primary and secondary data collection.

2.2. Steps Involved in Design of the Turbine. To start the initial design, calculations will be conducted to size turbine parts. The theory behind these is mainly taken from the "Micro Hydro Pelton Turbine Manual, by Thake [6]". Different assumptions are made in the design process using design guides and literature.

2.2.1. Calculation of the Net Head $\left(H_{n}\right)$. The net head at the nozzle exits can be expressed by the following formula [6]:

$$
H_{n}=H_{g}-H_{l} \text {, }
$$

where $H_{g}$ is the gross head and $H_{l}$ is total head losses due to the open channel, trash rack, intake, penstock, and gate or valve. These losses approximately equal 5\% of gross head [6]. This makes the net head available at the end of penstock as $50 \mathrm{~m}-2.5 \mathrm{~m}=47.5 \mathrm{~m}$.

2.2.2. Selection of Turbine. For the proposed site data head, $50 \mathrm{~m}$, and flow rate, 140 liter/sec combination (from Table 2), 
TABLE 3: Calculation summary to determine the turbine speed $(N)$ and PCD.

\begin{tabular}{|c|c|c|c|c|c|c|}
\hline Name & Symbol & Unit & & & & \\
\hline Number of jets & $n_{\text {jet }}$ & - & 1 & 2 & 3 & 4 \\
\hline Jet diameter & $d_{\text {jet }}$ & $\mathrm{mm}$ & 77.0 & 54.4 & 44.4 & 38.5 \\
\hline Runner PCD & PCD & $\mathrm{m}$ & 699.667 & 494.740 & 403.953 & 349.834 \\
\hline Available PCD & PCD & $\mathrm{mm}$ & 700 & 500 & 425 & 350 \\
\hline Turbine speed & $N$ & $\mathrm{rpm}$ & 371 & 520 & 611 & 742 \\
\hline Gear ratio & $X$ & - & 4.04 & 2.89 & 2.45 & 2.02 \\
\hline
\end{tabular}

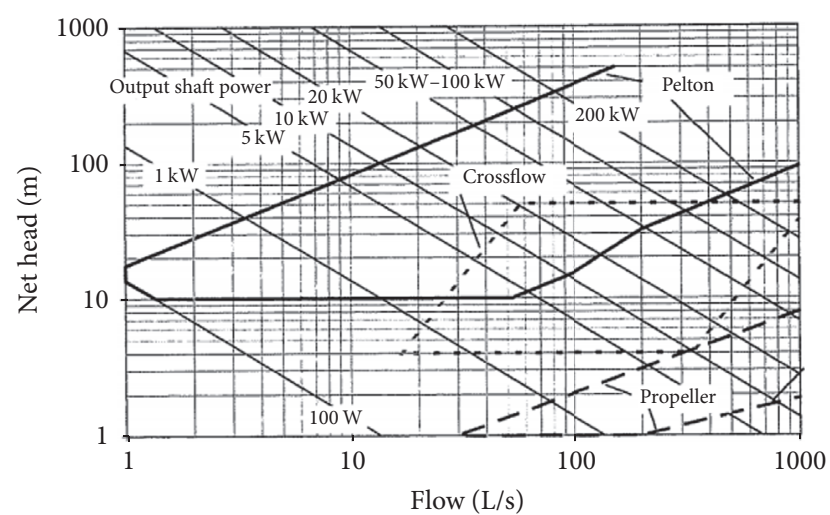

Figure 2: Application ranges for different types of turbine [6].

principally a choice was necessary between Pelton and cross flow situations as shown in Figure 2. The figure shows the approximate application ranges of turbines for micro hydro. Therefore, this chart can be used for selection of the turbine type. The area highlighted in solid line shows an indicative range of operation for the Pelton runner used in this research paper.

2.2.3. Calculation of Jet Diameter $\left(d_{J e t}\right)$. The pressure at the bottom of the penstock creates a jet of water with velocity, $V_{\text {jet }}$

$$
V_{\text {jet }}=K_{N} \sqrt{2 g H_{n}}
$$

where $V_{\text {jet }}$ is jet velocity $(\mathrm{m} / \mathrm{s}), K_{N}$ is nozzle velocity coefficient (normally around 0.95 to $\mathbf{0 . 9 9}$ ), and $H_{n}$ is net head at the nozzle. The flow rate $(Q)$ is then given by this velocity multiplied by the cross-sectional area of the jets:

$$
\begin{aligned}
Q & =A_{\text {jet }} \times V_{\text {jet }} \times n_{\text {jet }} \\
& =\Pi \frac{d_{\text {jet }}^{2}}{4} \cdot V_{\text {jet }} \cdot n_{\text {jet }},
\end{aligned}
$$

where $n_{\text {jet }}$ is number of jets and $d_{\text {jet }}$ is diameter of jets (m)

Combining (2) and (3) and using an average value of 0.97 for $K_{N}$, then solving for $d_{\text {jet }}$ becomes

$$
d_{\text {jet }}=\frac{0.54}{H_{n}^{1 / 4}} \cdot \sqrt{\frac{Q}{n_{\text {jet }}}} .
$$

The next step in the turbine design process is to determine the pitch circle diameter (PCD) of the turbine.

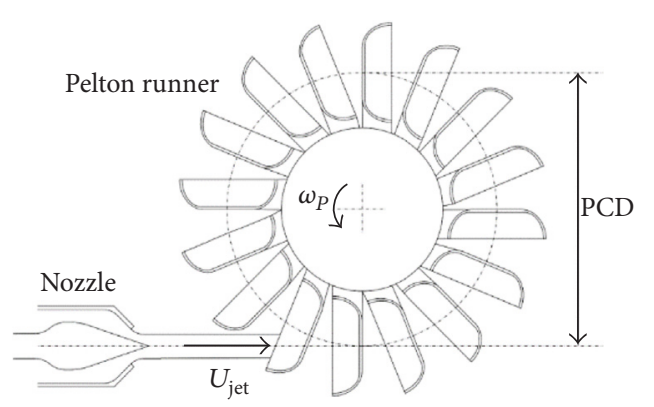

Figure 3: Diagram of a Pelton runner showing PCD [6].

2.2.4. Calculation of the Runner Circle Diameter (PCD). Figure 3 shows a schematic of a Pelton runner with a pitch circle diameter $D(=2 R)$ rotating at angular velocity $\omega_{p}$.

Beginning with the derived formula to determine the turbine speed which can be expressed as

$$
2 \pi \frac{N}{60} \cdot \frac{D}{2}=x \cdot V_{\text {jet }},
$$

where $(D)$ or PCD is pitch circle diameter $(\mathrm{m})$ and $x$ is ratio of runner velocity to jet velocity ( $x=0.46$ is used to produce the maximum power out of the turbine) [6]. $N$ is rotational velocity of runner (rpm). Substituting for $V_{\text {jet }}$, from (2), and using $x=0.46$, (2) becomes

$$
D=37.7 \times \frac{\sqrt{H_{n}}}{N} .
$$

A spreadsheet is prepared as shown in Table 3 to determine the turbine speed $(N)$ and PCD.

From Table 3 all the gear ratios are possible with belt drives. From the result in Table 3, runner pitch diameters (D) of $350 \mathrm{~mm}$ and $425 \mathrm{~mm}$ with 4 -jet and 3-jet turbine, respectively, have smaller pitch diameter. However, for a turbine of these powers making is very complex and needs considerable expertise, so these are probably not an option [6]. The single jet solution is possible, but a $700 \mathrm{~mm}$ PCD runner makes a very big turbine. The best solution is the $500 \mathrm{~mm}, 2$-jet turbine. Therefore, we can take the PCD to be $500 \mathrm{~mm}$ in our design analysis. To estimate the final system power output, efficiency values for the nozzles, turbine, and generator can be assumed. Thake [6] provides reasonable values for each. Table 4 shows the values of assumed efficiency in this research.

The equations used to determine the different design parameters of wheel are collected in Table 5. 


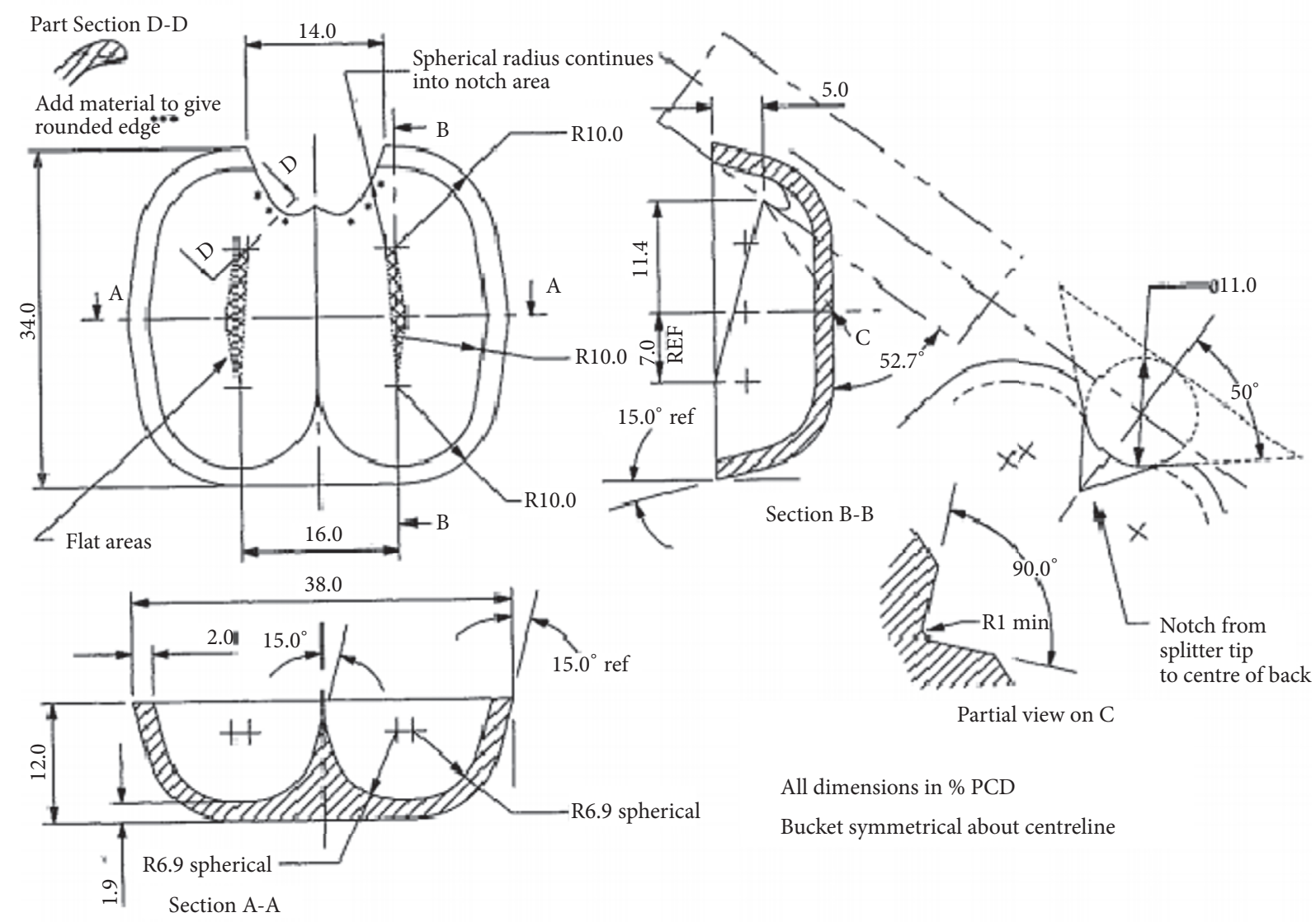

Figure 4: A scalable Pelton bucket. All dimensions are in \% of PCD [6].

TABle 4: Pelton turbine parts' assumed efficiency [6].

\begin{tabular}{lcc}
\hline Part & Symbol & $\begin{array}{c}\text { Assumed } \\
\text { efficiency }\end{array}$ \\
\hline Penstock & $\eta_{p}$ & 0.95 \\
Manifold & $\eta_{m}$ & 0.98 \\
Nozzle & $\eta_{n}$ & 0.94 \\
Runner & $\eta_{r}$ & 0.8 \\
Drive & $\eta_{d}$ & 1 \\
Generator & $\eta_{g}$ & 0.8 \\
\hline Overall efficiency & $\eta_{o}$ & 0.56 \\
\hline
\end{tabular}

2.2.5. Detail Bucket Geometry Design. Figure 4 shows the dimensions of the bucket as percentage values of the PCD of the turbine. Like the basic bucket model changing the PCD value within the model allows it to be scaled [6]. The physical dimensions of the bucket for the selected site data based on empirical relations for $500 \mathrm{~mm}$ PCD are shown in Table 6 which is used in this report for modeling of the bucket.

A basic stem for machining, used for bolting or clamping the buckets to the hub, is shown in Figure 5. Bolted buckets are an ideal solution for this research and are chosen as discussed in [6].

From all the above calculated parameters in Table 6 and some standard parameters using Figures 4 and 5, the

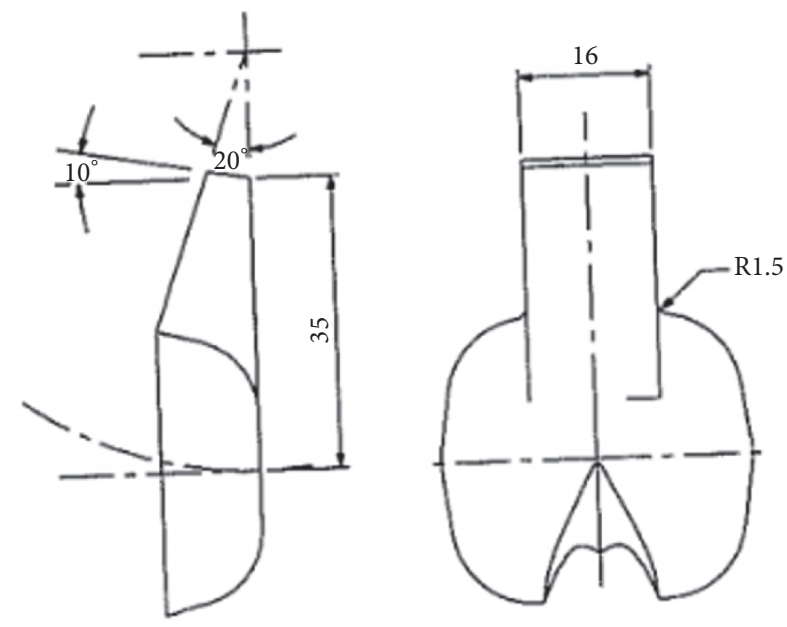

FIgURe 5: A basic bucket stem design for bolted fixing. All dimensions are in \% PCD [6].

modeling of the bucket is done using CATIA V5 software as shown in Figure 6(a). The bucket design was specified by defining the outline of the bucket using the dimensions given in Figures 4 and 5.

The basic bucket model was adapted to form an entire bucket by the use of patterning. Two-disc plate was used to 
TABLE 5: Basic design calculation summary of Pelton turbine.

\begin{tabular}{|c|c|c|c|}
\hline Descriptions & Data & Unit & Design guidelines Thake 2000 [6] \\
\hline$H_{\text {-net turbine }}$ & 46.5 & $\mathrm{~mm}$ & $H$-net turbine $=H_{\text {-net }} \times$ manifold efficiency \\
\hline$K_{N}$ & 0.97 & - & Ranges (between 0.95-0.99). \\
\hline$V_{\text {-jet }}$ & 29.6 & $\mathrm{~m} / \mathrm{s}$ & Velocity of the jet (for $n_{\text {jet }}=2$ ) \\
\hline$d_{\text {-jet }}$ & 54.4 & $\mathrm{~mm}$ & Diameter of the jet (for $\left.n_{\text {jet }}=2\right) d_{\text {jet }}=0.11 \times$ PCD \\
\hline$x(U / V$-jet $)$ & 0.46 & - & For maximum power output (blade speed $/ V$-jet) ratio \\
\hline Bucket speed & 13.6 & $\mathrm{~m} / \mathrm{s}$ & $U=x \cdot V_{\text {jet }}=0.46 \times 29.6$ \\
\hline$N$ & 1500 & Rpm & Standard generator RPM \\
\hline$N-r$ & 1170 & Rpm & Runaway speed $=1.8$, turbine optimum speed \\
\hline$\eta$ & 0.56 & & Total system efficiency \\
\hline$P$ & 36.57 & $\mathrm{~kW}$ & Estimated electrical power $=\rho g H_{\text {-net }} \times Q \times \eta_{0}$ \\
\hline$P$-turbine & 51.2 & $\mathrm{~kW}$ & Turbine mechanical power $=\rho g H$-net turbine $\times Q \times \eta_{r}$ \\
\hline
\end{tabular}

TABLE 6: Physical baseline bucket dimensions result for the selected site data.

\begin{tabular}{|c|c|c|c|}
\hline Parameters, formula [6] & Calculation & Dimensions/result & Unit \\
\hline Height of bucket, $h=0.34 D$ & $h=0.34 \times 500$ & 170 & $\mathrm{~mm}$ \\
\hline Cavity length: $h 1=5.6 \% D$ & $h 1=(0.056) \times 500$ & 28 & $\mathrm{~mm}$ \\
\hline Length to impact point: $h 2=0.114 D$ & $h 2=0.114 \times 500$ & 57 & $\mathrm{~mm}$ \\
\hline Width of bucket opening, $a=0.14 D$ & $a=0.14 \times 500$ & 56 & $\mathrm{~mm}$ \\
\hline Bucket thickness: $t 1=0.002 \mathrm{D}$ & $t 1=0.002 \times 500$ & 1 & $\mathrm{~mm}$ \\
\hline Approximate number of buckets, $Z$ & $Z=D / 2 d+15$ & 18 & \\
\hline Depth of the bucket, $t=0.121 \mathrm{D}$ & $t=0.121 \times 500$ & 60.5 & $\mathrm{~mm}$ \\
\hline Width of the bucket, $b=0.38 \mathrm{D}$ & $b=0.38 \times 500$ & 190 & $\mathrm{~mm}$ \\
\hline
\end{tabular}

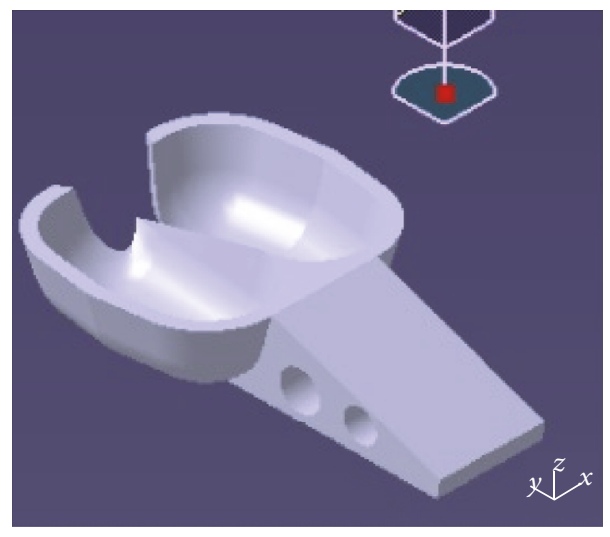

(a)

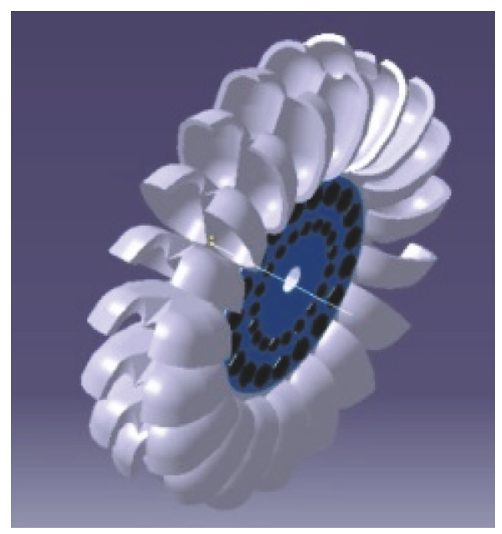

(b)

Figure 6: Solid model of Pelton turbine for the selected site data, (a) bucket and (b) 3D view of the runner right.

mount the buckets circularly as shown in Figure 6(b). The discs were to sandwich the buckets into place.

\section{Computational Analysis}

For the selected Melkey Herra's micro hydro power site, Pelton turbine was the most suitable hence chosen for our numerical performance analysis. The main dimensions of the turbine examined here correspond to this ideal plant. The numerical techniques created during this section included many numerical and physical assumptions to simplify the problem. This was necessary because accurate modeling of impulse turbines (Pelton in this case) that include complex phenomena like free surface flow, multifluid interaction, rotating frame of reference, and unsteady time dependent flow is a challenge from a computational cost point of view [10-18].

3.1. Physical Assumptions and Scaling Down. The computational domain was created removing the features that were 
TABLE 7: Turbine geometry and setup values for prototype and model.

\begin{tabular}{lcccc}
\hline Parameters & Symbol & Unit & $\begin{array}{c}\text { Prototypes' } \\
\text { values }\end{array}$ & $\begin{array}{c}\text { Selected model } \\
\text { operating condition }\end{array}$ \\
\hline Flow rate & $\mathrm{Q}$ & Lts/s & 140 & 20.84278 \\
Head & $H$ & $\mathrm{~m}$ & 47.5 & 13.34275 \\
PCD & $D$ & $\mathrm{~mm}$ & 500 & 265 \\
Bucket width & $B$ & $\mathrm{~mm}$ & 190 & $100.7>80 \mathrm{~mm}$ \\
Power & $P$ & KW & 51.2 & 2.14 \\
Number of & $Z$ & & $\mathbf{1 8}$ & $\mathbf{1 8}$ \\
buckets & & & \\
\hline
\end{tabular}

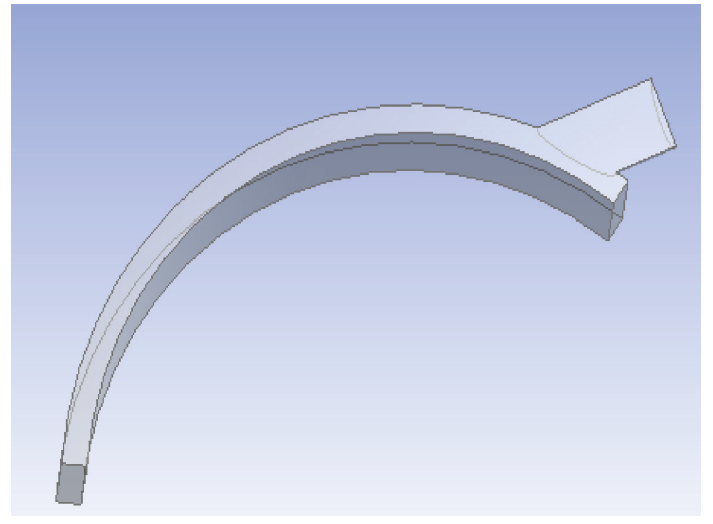

(a)

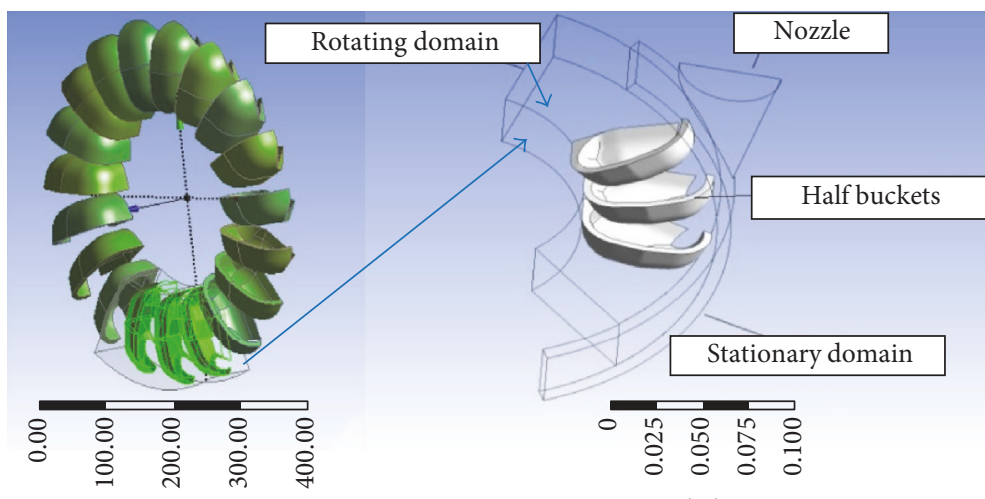

$(\mathrm{mm})$ (m)

(b)

FIGURE 7: Domain geometries: stationary (a) and assembly of the rotating and stationary domain (b).

assumed to have no or minor effect when comparing the runner designs as follows. The following are some of the simplifying assumptions made in the analysis.

No Casing. Modeling the Pelton turbine without casing, similar methods can be found in the literatures $[10,11]$.

Symmetry. To reduce computational cost, the buckets, nozzle, and water-jet are cut in half at the symmetry axis $[10,11]$.

Single Jet. Modeling of only the single jet operation was found in most of the publications reviewed in Section $1[10,11]$.

No Hub. The flow will not be interacting with any other part of the runner except for the bucket. Hence, there is no need to include the hub into the CFD model, as suggested in the literatures $[10,11,13]$.

Periodic Torque. Three buckets are enough to recreate the complete runner torque and are used also in this research $[10,11]$.

"Similitude". Similitude in a general sense is the indication of a known relationship between a model and a prototype. Equation (7) represents head coefficient, flow coefficient, and power coefficient for model studies [10]. In order to achieve similarity between model and prototype behavior, all the corresponding terms must be equated between model and prototype. So, the model is presumed to have the same values of speed ratio, flow ratio, and specific speed.

$$
\begin{aligned}
& \left(\frac{H}{D^{2} N^{2}}\right)_{\text {prototype }}=\left(\frac{H}{D^{2} N^{2}}\right)_{\text {model }}, \\
& \left(\frac{Q}{N D^{3}}\right)_{\text {prototype }}=\left(\frac{P}{N D^{3}}\right)_{\text {model }}, \\
& \left(\frac{P}{D^{5} N^{3}}\right)_{\text {prototype }}=\left(\frac{P}{D^{5} N^{3}}\right)_{\text {model }} .
\end{aligned}
$$

Scaling Down. Scaling down of the prototype is also important to reduce the time consumption and to ease the computational processing in normal computers. On the basis of the above considerations, the scaling factor of 0.53 was used to meet the minimum bucket width standard for model testing, and the Reynolds number also needs to be greater than $2 \times 10^{6}$. This is based on the international standard IEC 60193 of the International Electrotechnical Commission which applies to laboratory testing of model turbines [10, 23]. In this standard, the factor greater than 0.28 was found to satisfy IEC 60193 criteria for Pelton turbines.

Table 7 shows the values for prototype and model with the same speed of $520 \mathrm{rpm}$.

3.2. Computational Domain Creation. Figure 7 depicts the completed CAD drawings of the rotating and stationary 


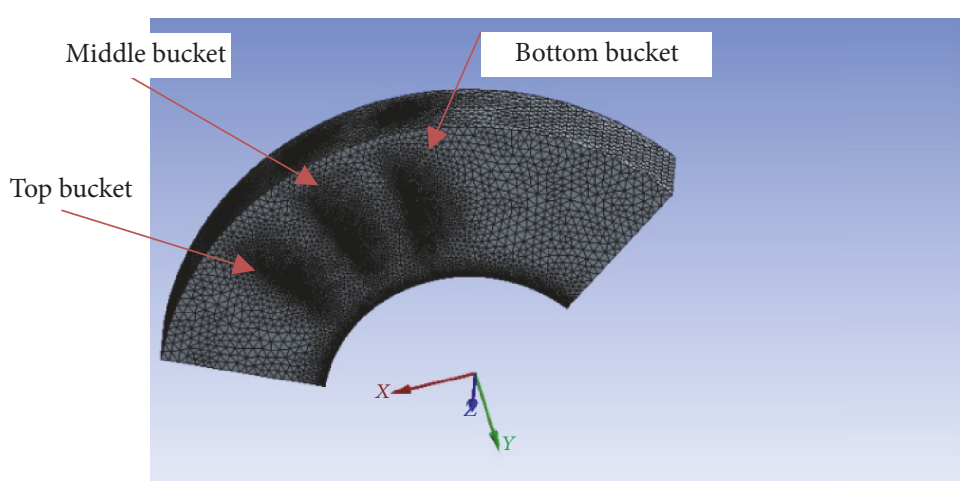

(a)

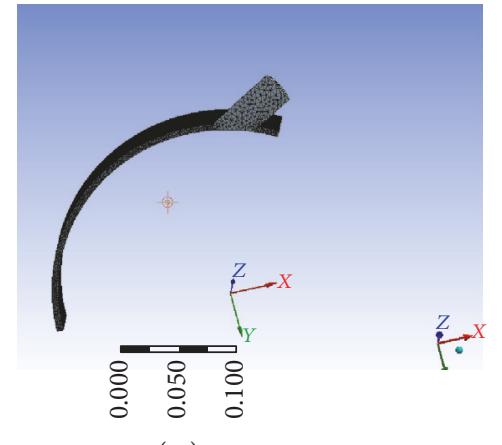

(m)

(b)

FIGURE 8: Meshed rotating (a) and stationary domain (b) sizing and inflations were applied.

domain which is modeled separately and assembled here to show their relative initial positions. Stationary domain contains half a cylinder for the inlet and a ring to accommodate an interface between the two domains.

Imagine that the rotating domain in Figure 7 is aligned with the stationary domain. When the rotating domain leaves this position, another identical domain is introduced at the top (the same geometry). Thus, one achieves a continuous simulation of a runner [11].

3.3. Meshing. Figure 8 shows both stationary and rotating domains meshed as they are imported into CFX-Pre. As suggested in the literature $[10,19]$, unstructured tetrahedral elements were used for the rotating domain meshing because of more complex geometry to be captured by the mesh and also to allow automatic meshing for all the upcoming geometry modifications. In order to determine the minimum grid size or mesh resolution required to resolve the boundary layer and the mean flow features, a grid independence study was conducted. This allows minimization of errors and uncertainties in the predicted results, for example, the runner power output or the efficiency. Therefore, grid convergence analysis has been carried out considering power output (in this study by monitoring torque) as a parameter of significant interest. The results of grid independence study are presented in Section 3.6.

3.4. Physical Setup with ANSYS Preprocessing. In this section, the essentials of the ANSYS Pre setup are presented.

Analysis Type. In each "Flow Analysis" in ANSYS Pre there is a tab called "Analysis Type." This is where one defines whether or not the simulation is transient or steady-state, control simulation time and time steps. In this case, the transient option was chosen. Time steps are interval for which CFX solver calculates flow parameters in transient analysis. The time step was $1 / 20$ total time, which corresponds to $0.001714 \mathrm{sec}$ to capture 20 time frames per rotation.

Multiphase Model. The flow through the penstock pipe is having only single phase for the fluid. As the water-jet comes out of the nozzle, it is directly freed to the atmosphere and the effect of free water-jet will come into picture. This flow passes through runner buckets, and it will be a free surface flow. This free surface flow glides through internal surface of the buckets and the momentum transfer takes place. The flow leaving the runner bucket will be converted into dispersed water droplets as the fluid leaves contact from the buckets. This way the flow through the Pelton turbine is multiphase in nature in agreement with the literatures $[10,11,13,14]$. To capture the flow accurately, homogenous multiphase analysis is performed in this research.

Volume Fraction of Water. As suggested by the literature [5], the volume fraction of water should change from 0 to 1 . In each control cell, the volume fractions of the water and air sum to $1, \alpha_{w}+\alpha_{g}=1$. Then $\alpha_{w}=0$ denotes cells filled with air, while $\alpha_{w}=1$ denotes cells filled with water and $0<\alpha_{i}<1$ denotes that the cell contains an interface between the water and air. In the beginning of the simulation, both domains are full of air with $0 \mathrm{~m} / \mathrm{s}$ velocity. Therefore, the given initial conditions are $0 \mathrm{~m} / \mathrm{s}$ velocity and $0 \mathrm{~Pa}$ for relative pressure. Initial water volume fraction is 0 and initial air volume fraction is 1 .

Turbulence Model. Shear Stress Turbulence (SST) model is able to capture turbulent scales in flow in high shear stress regions $[10,11]$. So SST turbulence model is chosen for further simulations.

Domain Interface. The interface type between the stationary and rotating domains was Fluid-Fluid $[10,11]$. Interface model for this type was General Connection and the Transient Rotor Stator option was selected for Frame Change/Mixing Model. Pitch ratio was maintained to value 1 between domain interfaces by maintaining equal area in interface region. To apply a rotation to the rotating domain, domain motion in the rotating domain was set to rotating, and angular velocity was defined by the expression "Omega." In this case, the angular velocity is negative because the domain was modeled to rotate in the negative rotation direction about the $z$-axis. This method is also found in the literatures $[10,11,14]$. 
TABLE 8: Expressions defined in ANSYS Pre for the baseline design $[5,11]$.

\begin{tabular}{lcc}
\hline Name & Expression & Description \\
\hline Gravity & $9.82\left[\mathrm{~ms}^{-2}\right]$ & Acceleration due to gravity \\
Head & $13.34[\mathrm{~m}]$ & Model head based on scaling \\
Turbine radius & $132.5[\mathrm{~mm}]$ & Model turbine radius based on scaling \\
Inlet velocity & $(2 \times \text { gravity } \times \text { head })^{0.5}[\mathrm{~m} / \mathrm{s}]$ & Water velocity at the nozzle inlet \\
Omega & Inlet velocity/ $(2 \times$ turbine radius $)[\mathrm{rad} / \mathrm{s}]$ & Angular velocity: rotation in the negative direction is selected \\
Torque middle bucket wall & Torque_z@Middel Bucket Wall & The entire middle bucket is selected \\
Total time & $((120 \times$ pi $) / 180) /$ Omega & Total simulation running time \\
\hline
\end{tabular}

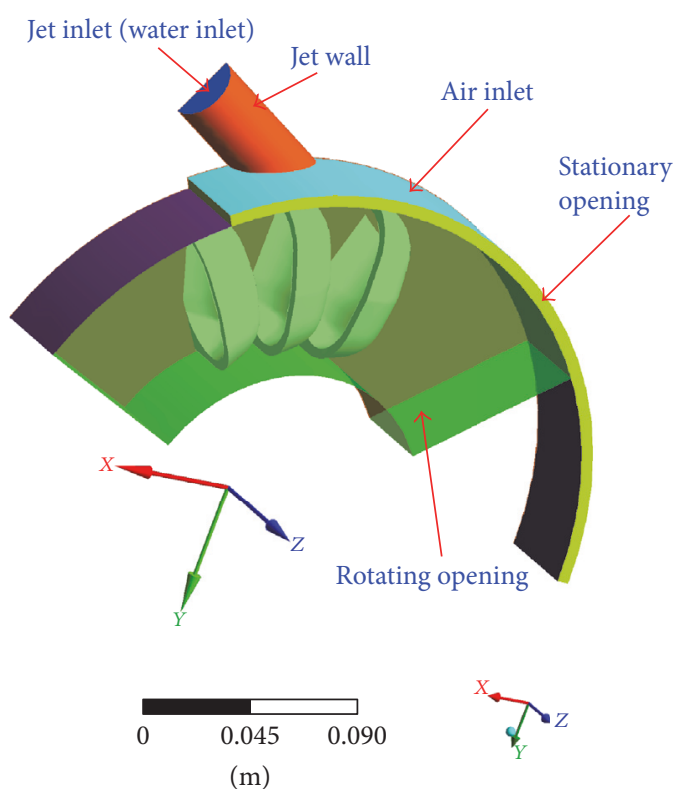

(a)

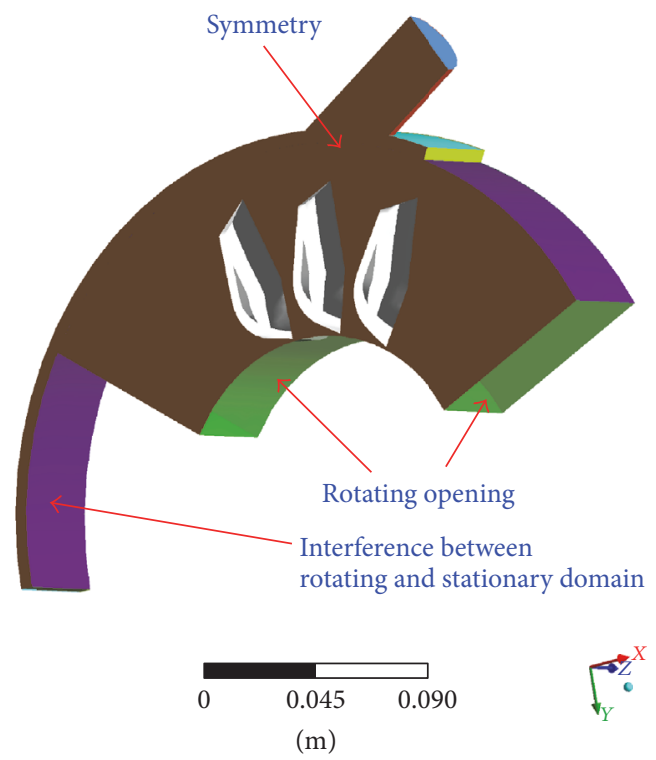

(b)

Figure 9: Boundaries applied on the domains.

Boundary Condition in Rotating Domain. This section contains a list of boundaries and their conditions. No boundary for outlet is defined in the rotating domain. Rather, opening type boundary condition has been defined. The bucket surface is defined by wall type boundary condition and an interface type boundary condition at interface between the rotating and stationary domain. All other remaining boundaries are defined as opening type since it is unpredictable about the actual outlet and flow pattern of fluid through the runner. An overview of the boundary conditions can be found in Figure 9.

Solver Control and Output. The chosen advection scheme was High Resolution according to the CFX Modeling Guide. This gives a good compromise between robustness and accuracy. Second-Order Backward Euler option was selected for the Transient Scheme as it is generally recommended for most transient runs in CFX $[5,10,11,13,14]$.

Monitor Points. The main output of the simulation is the total torque on the middle bucket. A monitor for the expression "Torque on Middle Bucket Wall" was added, which logged the torque and made it possible to monitor the torque during the simulation. The calculated torque data on the middle bucket was extracted from the simulation using an inbuilt torque function applied to the Named Selections created for the regions for the middle bucket. This function is then plotted as a Monitor Point, while the simulation runs, allowing the calculated torque at each time step to be exported.

Expressions. Defining expressions is a good way of streamlining a CFD case. The expressions in Table 8 are used in the setup. This way of defining expressions can be also found in the literatures $[5,11]$.

3.5. Result and Discussion. In general rule, a small runner is cheaper to manufacture than the larger one. It takes less material to cast it and the housing and associated components also can be smaller. For this reason, consequences of reducing PCD $(=400 \mathrm{~mm})$ from the baseline design $(\mathrm{PCD}=500 \mathrm{~mm})$ are evaluated and results are compared with those published by Panthee et al. [10] and Panagiotopoulos et al. [19], respectively. The geometrical characteristics of their Pelton turbine model used for their study correspond to a Pelton 


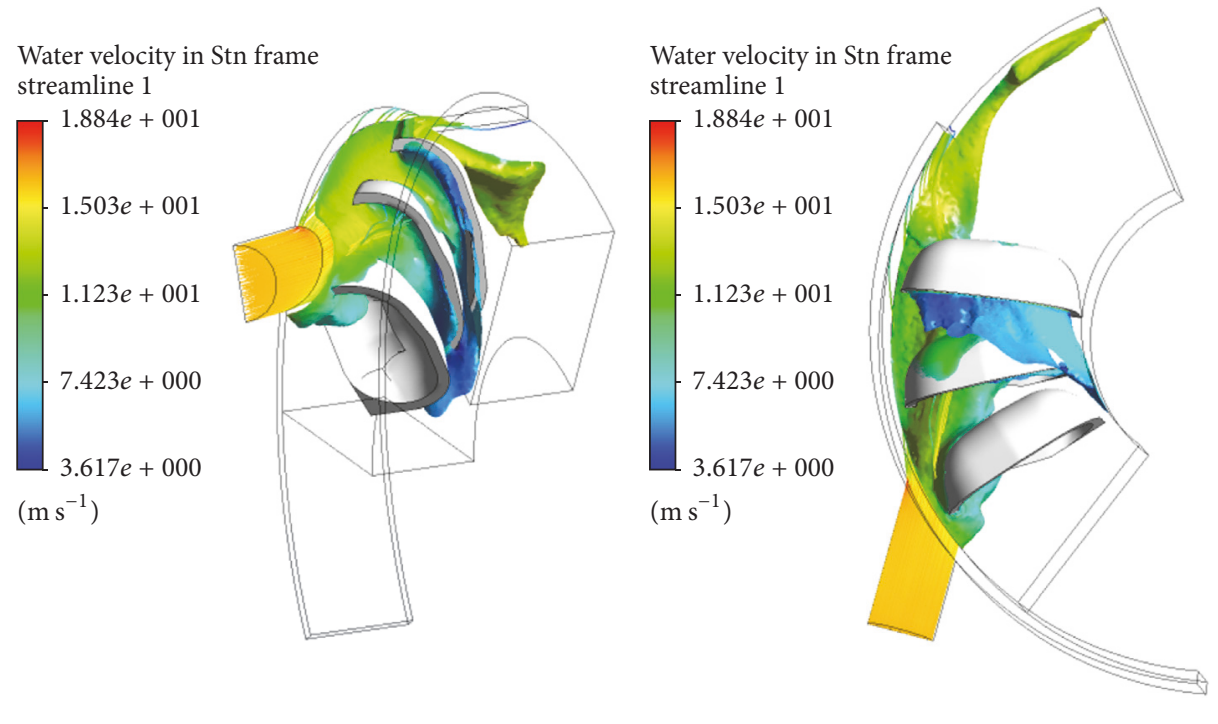

Figure 10: Flow visualization of the baseline design, side views, and face views (PCD $=500 \mathrm{~mm})$.

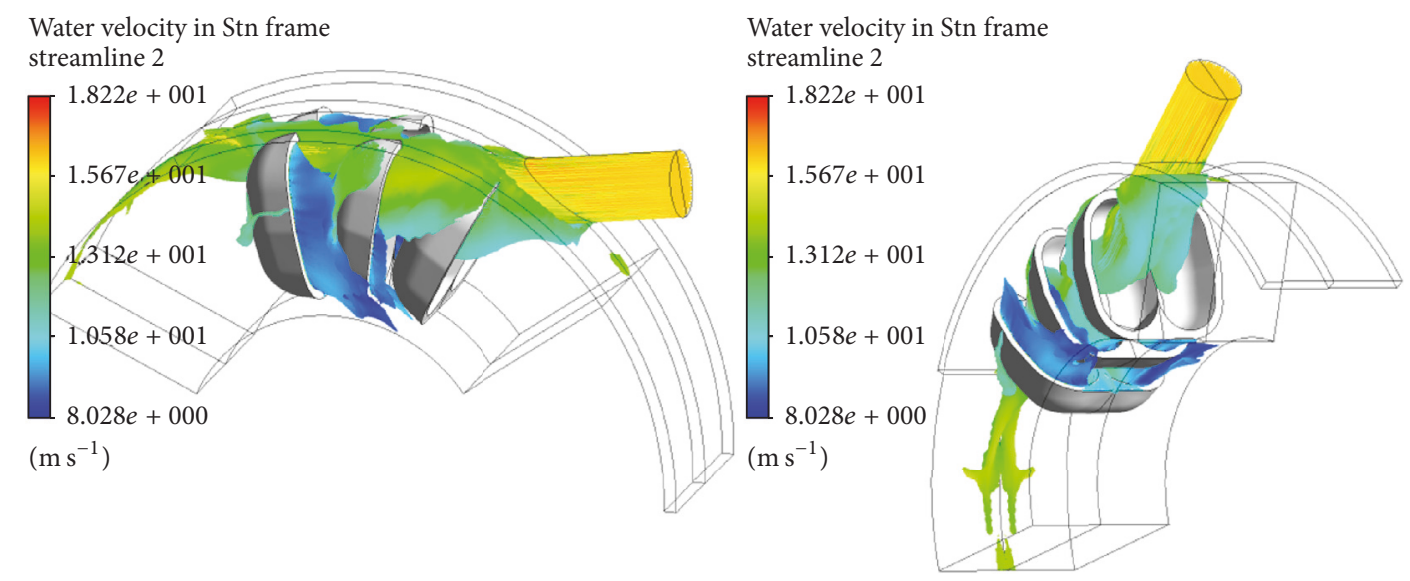

FIGURE 11: Flow distribution of the runner: water velocity in Stn frame, side views, and face views (PCD $=500 \mathrm{~mm})$.

turbine installed in Khimti Hydropower in Nepal [10] and the National Technical University of Athens [19], respectively. The PCD of the model runner for both power plants was $400 \mathrm{~mm}$, and the axis is horizontal with two injectors.

Next, a visualization of the flow in the turbine buckets for this study can be seen in Figure 10.

As seen in Figures 10 and 11, only very small amount of "leaked" water is present next to the bottom bucket with low jet velocity. These visualizations give good information about the flow pattern. The streamlines that came from the nozzle entered into the runner, hitting the buckets and dividing the jet into three portions (Figures 10 and 11). First, the portion from the bottom of the jet touched the outside and inside of the top bucket that is close to the nozzle. The second portion of the jet was the one from the middle, which hit the next middle bucket. Finally, the rest portion of the jet crossed into the latter bucket. On the face and side view on Figure 10, one can observe the part of the flow escaping from the cutout of the bucket as well as the lateral sheet flow.
It can be observed on Figure 12 that the maximum pressure point, in red, corresponds to the PCD of the bottom bucket and the tip of the middle bucket which is aligned with the axis of the impinging jet. Similar finding is observed in the literature [10].

As seen in Figure 13, when the PCD is reduced to $400 \mathrm{~mm}$, a large amount of water does not leave the buckets, causing severe backwash on the backside of the bucket, which varies from certain sound value at the place of impingement to the reduced values as water goes outward (Figure 13(b)). However, there is a small amount of the flow that leaves through the cutout with high velocity without being utilized (cutout leakage). This phenomenon has to be reduced during the optimization stage.

The water is unevenly distributed across the buckets and there are several local accumulations of cells with a high volume fraction of water, most visible in the bottom bucket in Figure 14. This volume of fraction of water will vary with time as the buckets rotate. This occurs when the portion of 


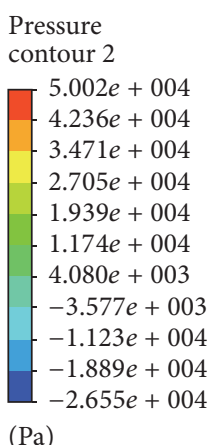

$(\mathrm{Pa})$

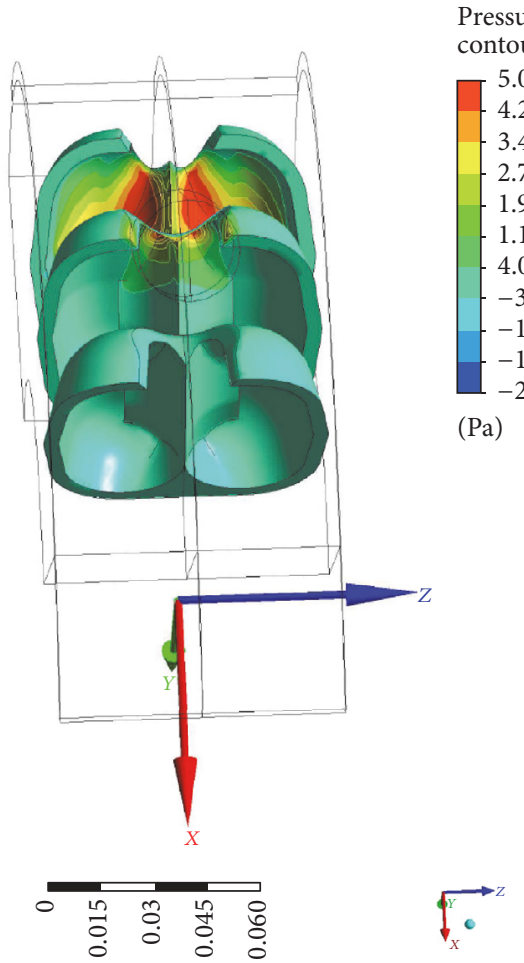

(m)

(Pa)

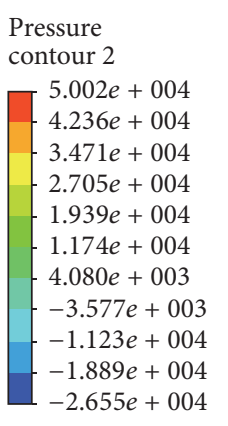

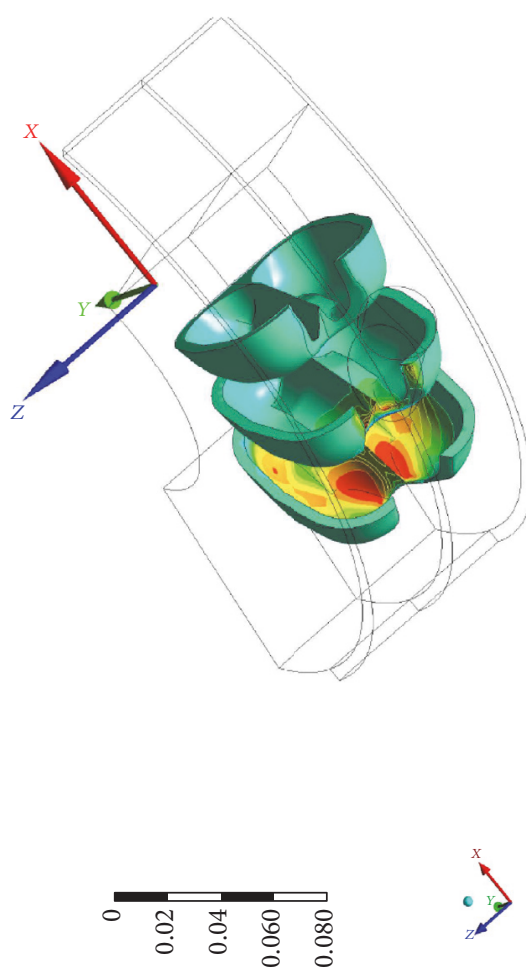

(m)

(m)

Figure 12: Pressure contours on the bucket $(\mathrm{PCD}=500 \mathrm{~mm})$.

the jet is going to leave out completely from the bottom bucket and completely enters the next top and consequential buckets. The red and blue regions show, respectively, water and air in the computational domain. In a more complex situation, the atmosphere also exerts pressure on the surface (water-vapor interface) [24].

Looking at Figures 13(b) and 14, it is clear that, as the water starts entering into the top bucket, the inner surface of the middle and bottom bucket will still be having some water volume fraction inside it. It means that, for a particular instance of time and runner rotation, more than one of the runner buckets are having water volume fraction. The amount of the water flow touching the runner bucket sides and back surface of the bucket (backwash) is also visible. This water fraction at the back side and side surface of the bucket will impart some force to the buckets and if this fraction is high, then the intensity of force on the bucket will be higher and it will reduce the strength of the buckets $[11,13,14]$. Another effect of this is that the water is acting as a brake on the runner, rather than helping it turn, and this gives a serious loss of power. These energy losses occur with jet entering the bucket and providing some amount of counter-torque as the outer side of the bucket hits by the surface of the jet.

The pressure distribution in the bucket was due to impact of high jet. This pressure distribution applied on the bucket again varies with the time due to the rotation of the runner. It was found that the pressure peaks are obtained at bucket tip and PCD of the runner. The pressure peak in bucket tip is due to flow disturbance when jet strikes bucket tip. It is obvious to obtain the pressure peak at the runner PCD since the Pelton runners are designed such that it would convert most of the hydraulic energy to mechanical energy when the jet strikes the runner PCD. Result showed high pressure with the value of $3.559 \times 10^{4} \mathrm{~Pa}$ for the first top and the second middle bucket at some degree of rotation of the runner as shown in Figure 15. This pressure value is lower than the previous value when $\mathrm{PCD}=500 \mathrm{~mm}$ (Figure 12). This might indicate that there is energy loss in the runner.

The images in Figure 15 are taken of the right bucket half; then it is mirrored here to ease the comparison through symmetry. The next step will be focused on future simulations regarding the study of the hydraulic efficiency; a better approximation of the numerical torque.

The hydrodynamic torque and the hydraulic efficiency of the runner are computed after completing the evaluation of a jet-bucket interaction flow, starting from the moment of impingement (jet cut in) until the evacuation of the bucket (jet cutout) [11]. The calculations are then continued for the particles of the oncoming frames, until all particles of a frame impinge on the next coming bucket (jet cut). As can be observed in Figure 15, the shape of the torque curve is also similar to the previous studies by different authors $[10,19]$, but the irregularity of the curve in this area was attributed due to the Coanda effect and the impact of the back flow which creates counter-torque on the bucket and makes it slightly different from the previous studies $[5,11,19]$. Some indicative pictures from the turbine examined here show how the energy transfer occurred in a single bucket as illustrated in Figure 16. 


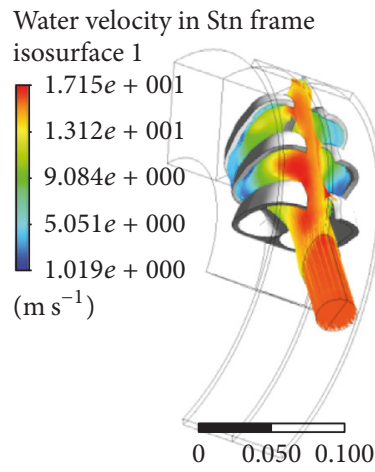

$(\mathrm{m})$

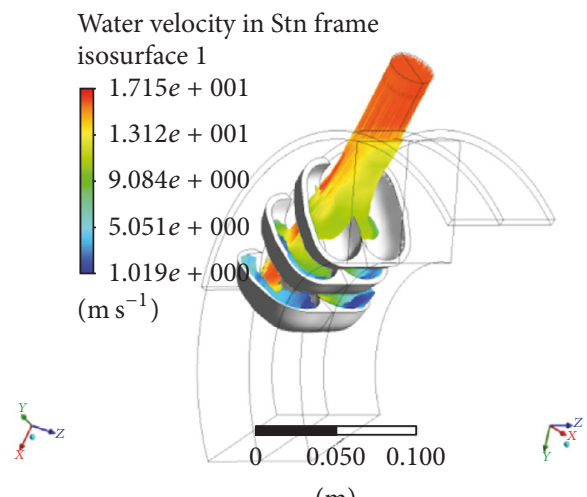

$(\mathrm{m})$

Water velocity in Stn frame isosurface 1
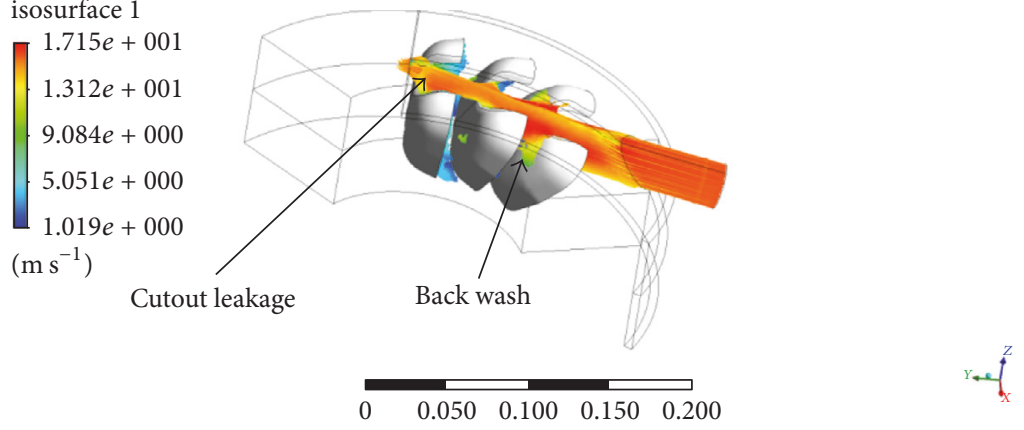

$(\mathrm{m})$

(a)

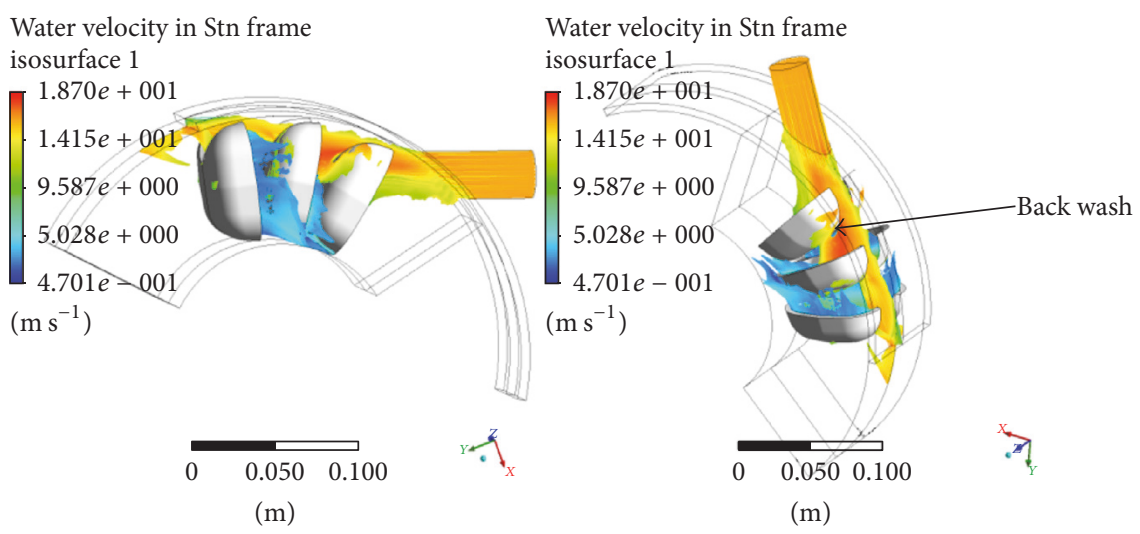

Water velocity in Stn frame isosurface 1
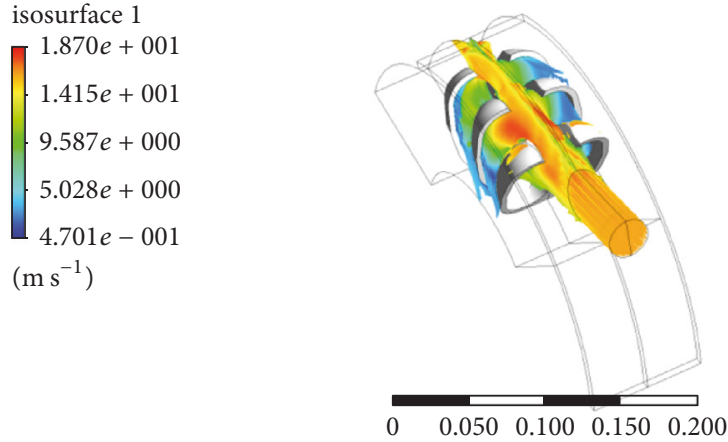

(m)

(b)

FIGURE 13: Flow distribution of the runner: water velocity in Stn frame, side views, and face views (PCD $=400 \mathrm{~mm})$. 


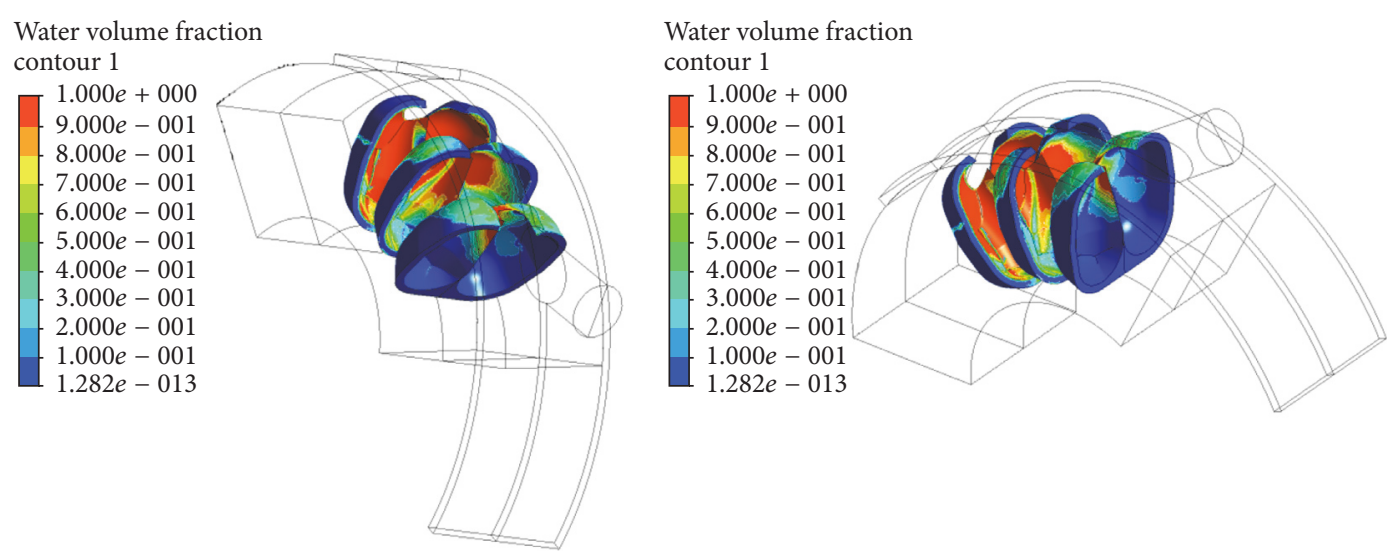

FIGURE 14: Volume fraction of water for reference bucket design at a particular time step (PCD = $400 \mathrm{~mm})$.
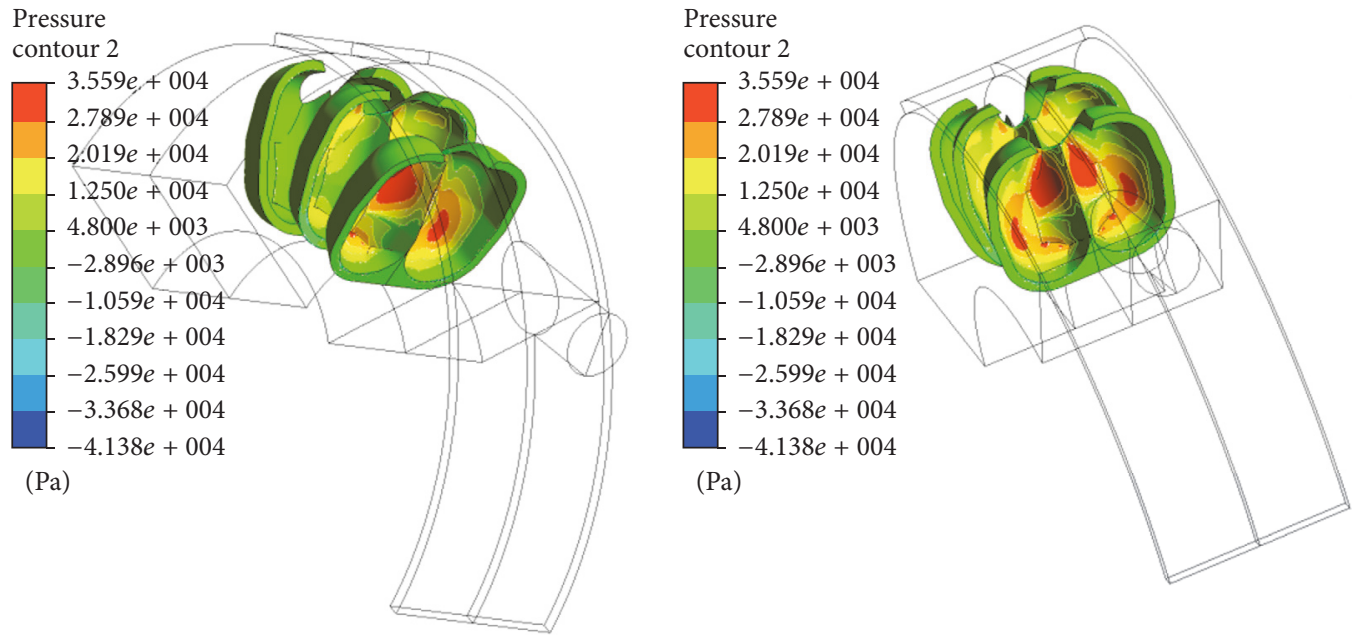

FIGURE 15: Pressure distribution at some degree of rotation of reference bucket design $(\mathrm{PCD}=400 \mathrm{~mm})$.

At the start (cut in) a counter-torque can also be observed caused by the interaction of the jet with the back surface of the bucket; this value is larger for PCD $=400 \mathrm{~mm}$ comparing to the baseline design (Figure 16). Just afterwards, the torque is increasing as more water interacts with the inner surface until the full jet interacts with the bucket to produce the maximum torque. The maximum torque produce by the baseline design $(500 \mathrm{~mm})$ is larger than that of a reduced PCD $(400 \mathrm{~mm})$. The result in Figure 16 shows also that smaller turbine is faster than the larger one which is true.

Next, the total curves of the complex unsteady flow in the bucket for the seven buckets analyzed can be acquired with the aid of time history views like the ones in Figures 17 and 18 . The total torque curve is shifted by the single blade passage phase for the whole range of total torque values and summed to give the total torque acting on the turbine shaft. In this research paper, the torque generated by the middle bucket is replicated over time to determine total torque generated by Pelton turbine. This is done by assuming that at stable conditions every bucket is producing identical torque periodically. The replication was done till the summation graph gave steady values which occurs after

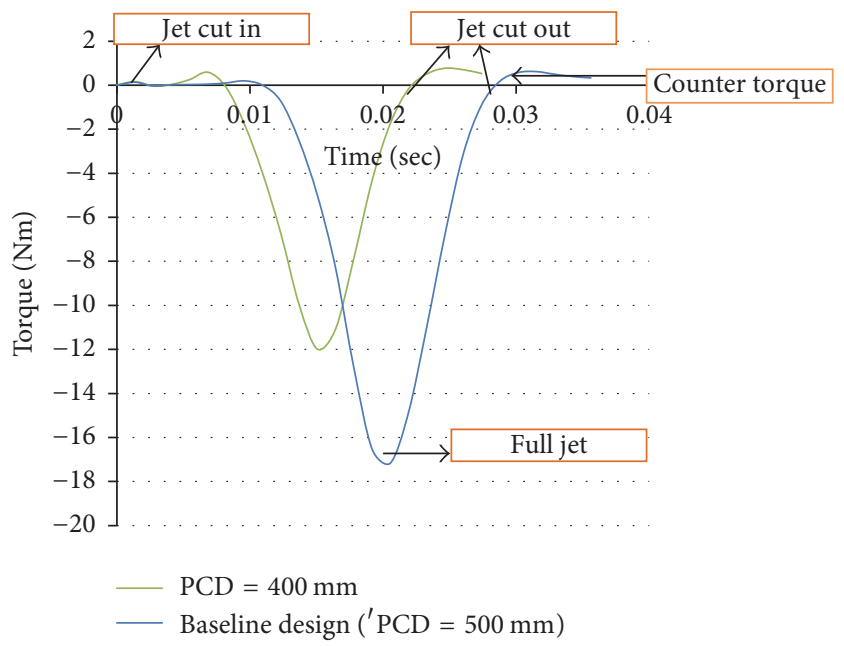

FIGURE 16: Torque generated by middle bucket versus time.

three buckets covered by the water sheets at $0.03 \mathrm{sec}$ of the rotation of the runner. The plot obtained was due to half 
TABLE 9: Mesh dependent test analyzed for PCD $=500 \mathrm{~mm}$.

\begin{tabular}{|c|c|c|c|c|c|c|c|c|}
\hline Mesh type & M1 & M2 & M3 & M4 & M5 & M6 & M7 & M8 \\
\hline Total number, elements & 294952 & 520687 & 2011665 & 2239650 & 2398044 & 2861243 & 3955723 & 5050204 \\
\hline Calculated total torque $(\mathrm{Nm})$ & -30.93 & -32.20 & -34.32 & -34.50 & -34.69 & -34.92 & -35.02 & -35.25 \\
\hline Standard torque (Nm) & -35.06 & -35.06 & -35.06 & -35.06 & -35.06 & -35.06 & -35.06 & -35.06 \\
\hline Torque error percent (\%) & 11.8 & 8.2 & 2.1 & 1.6 & 1.1 & 0.4 & 0.1 & 0.5 \\
\hline
\end{tabular}

TABLE 10: Mesh dependent test analyzed for PCD $=400 \mathrm{~mm}$.

\begin{tabular}{|c|c|c|c|c|c|c|c|c|}
\hline Mesh type & M1 & M2 & M3 & M4 & M5 & M6 & M7 & M8 \\
\hline $\begin{array}{l}\text { Total number, } \\
\text { Elements }\end{array}$ & 128251 & 128546 & 130961 & 2321026 & 3019180 & 4052422 & 4771226 & 6855793 \\
\hline $\begin{array}{l}\text { Calculated total } \\
\text { torque }(\mathrm{Nm})\end{array}$ & -18.13 & -18.15 & -18.29 & -21.84 & -22.15 & -22.27 & -22.37 & -22.41 \\
\hline $\begin{array}{l}\text { Standard torque } \\
(\mathrm{Nm})\end{array}$ & -28.05 & -28.05 & -28.05 & -28.05 & -28.05 & -28.05 & -28.05 & -28.05 \\
\hline $\begin{array}{l}\text { Torque error } \\
\text { percent }(\%)\end{array}$ & 35.4 & 35.3 & 34.8 & 22.1 & 21.0 & 20.6 & 20.2 & 20.1 \\
\hline
\end{tabular}

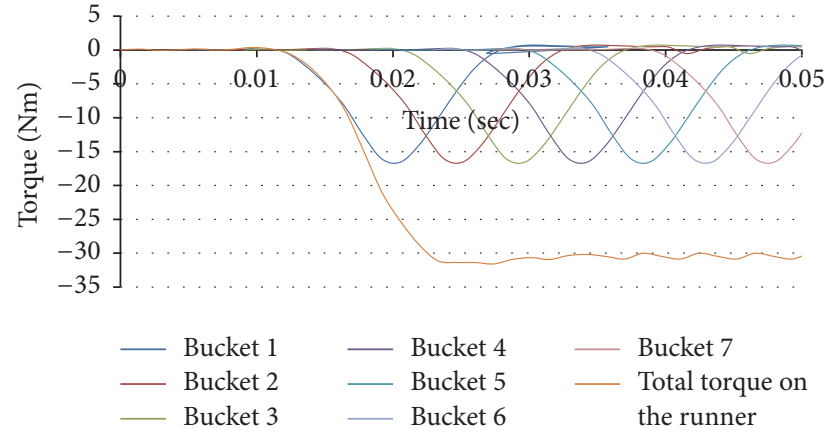

FIGURE 17: Dynamic runner and bucket torque over time for (PCD $=500 \mathrm{~mm}$ ).

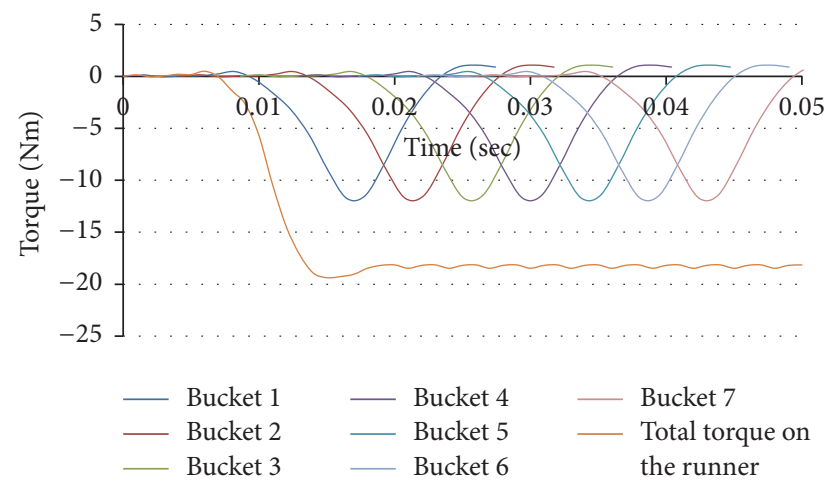

FIGURE 18: Dynamic runner and bucket torque over time for (PCD $=400 \mathrm{~mm}$ ).

nozzle and the maximum torque on the runner at a time is given by peak value multiplied by 4 as there are two nozzles in each unit. This runner torque has been taken for power output calculations by taking the average value from 0.03 to $0.05 \mathrm{sec}$ of the runner rotation. Methods of calculating the power output from a single bucket torque readings similar to those described above are quite common and can be found in the literature [10-12].

To calculate the efficiency, power input has to be calculated as well which for a complete turbine is calculated using two variables describing the flow conditions: the net pressure head and the flow rate [11].

$$
\begin{aligned}
P_{\text {input }} & =\rho g \mathrm{Q} H_{\text {net }}, \\
P_{\text {out }} & =\frac{2 \times \Pi \times N \times T}{60} .
\end{aligned}
$$

Therefore, (hydraulic) runner efficiency in this model was calculated using (9) as follows:

$$
\eta=\frac{P_{\text {output }}}{P_{\text {input }}} .
$$

The next validation phase is to compare efficiency of this model to the published results by Panthee et al. [10] and Panagiotopoulos et al. [19]. This will be done after checking the accuracy of the model, in agreement with the literature $[10,19]$.

3.6. Mesh Independency Study and Model Validation. Mesh or grid independent study is done in order to get a solution that does not vary significantly even when we refine our mesh further. Eight different mesh sizes were tested with an effective head of $47.5 \mathrm{~m}$ for two different cases. The mesh size on the rotating domain is controlled by element size. The relevance was increased for finer mesh. Afterwards, the orthogonal quality of the mesh has been checked and it was in an acceptable range (0.15-1.00) for each mesh developed. Each mesh was also created with the same physical setup and boundary conditions. During the simulations, results obtained were directly dependent on the accuracy in quality of mesh. And it was performed while analyzing the torque variation by developing the SST turbulence model.

Tables 9 and 10 indicate the grid information, the calculated torque, the standard torque, and the resulting modeled 
TABLE 11: Validation and performance prediction of Pelton runner.

\begin{tabular}{|c|c|c|c|c|c|c|c|c|c|}
\hline \multirow{2}{*}{$\begin{array}{l}\text { Parameters } \\
\text { Head }\end{array}$} & \multirow{2}{*}{$\begin{array}{c}\text { Unit } \\
\mathrm{m}\end{array}$} & \multicolumn{3}{|c|}{$\begin{array}{l}\text { Baseline design test } \\
\text { cases }\end{array}$} & \multicolumn{3}{|c|}{ Off- design test cases } & \multirow{2}{*}{$\begin{array}{c}\text { Published result } \\
\text { by Panthee et al. } \\
{[10]} \\
53.9\end{array}$} & \multirow{2}{*}{$\begin{array}{c}\text { Published result by } \\
\text { Panagiotopoulos et al. } \\
{[19]} \\
100\end{array}$} \\
\hline & & 47.5 & 53.9 & 100 & 47.5 & 53.9 & 100 & & \\
\hline Flow rate & $\mathrm{m}^{3} / \mathrm{s}$ & 0.14 & 0.05 & $\begin{array}{c}135 \% \\
\text { BEP }\end{array}$ & 0.14 & 0.05 & $\begin{array}{c}135 \% \\
\mathrm{BEP}\end{array}$ & 0.05 & $135 \% \mathrm{BEP}$ \\
\hline PCD & $\mathrm{mm}$ & 500 & 500 & 500 & 400 & 400 & 400 & 400 & 400 \\
\hline Runner speed & Rpm & 520 & 520 & 520 & 650 & 600 & 1000 & 600 & 1000 \\
\hline Number of buckets & - & 18 & 18 & 18 & 18 & 22 & 22 & 22 & 22 \\
\hline Model efficiency & $\%$ & 78.8 & 83.5 & 84.6 & 62.6 & 66.1 & 71.6 & 82.5 & 86.7 \\
\hline
\end{tabular}

runner efficiency for two different cases, namely, the baseline design $(\mathrm{PCD}=500 \mathrm{~mm})$ and the reduced size $(\mathrm{PCD}=$ $400 \mathrm{~mm})$, respectively.

The standard torque was calculated with the power obtained from power coefficient and the angular velocity of runner for comparison. One can observe that, from the result in Tables 9 and 10, a finer mesh will give a solution of a little higher accuracy than required but at the expense of computational power and time. About 3.9 million elements were required to obtain mesh independent result, for PCD = $500 \mathrm{~mm}$ (Table 9). Similarly, for the PCD $=400 \mathrm{~mm}$ turbine, a total number of 6.8 million mesh elements were required to obtain mesh independent results for the torque output (Table 10). A solution was considered grid independent for less than 0.3 difference in the torque output between three different consecutive mesh sizes. It appears that no significant enhancement is to be expected from a further refinement of the mesh. As seen from the results, a relative error of $20.1 \%$, between the CFD and the analytical data, was found for turbine with $\mathrm{PCD}=400 \mathrm{~mm}$ and $0.1 \%$ relative error for the baseline turbine $(\mathrm{PCD}=500 \mathrm{~mm}$ ) at the design-point operating condition $\left(Q=0.14 \mathrm{~m}^{3} / \mathrm{s}\right.$ and $\left.H=47.5 \mathrm{~m}\right)$. Hence, high value of relative torque error indicates that there are losses in the reduced size of the turbine, influencing the efficiency characteristics. The torque variation curves of the runner obtained using different density meshes are also presented in Figures 19 and 20.

Table 11 shows the performance prediction and comparison of the model results with two published results.

The computational analysis results presented in Table 11 showed that the performance of the baseline's turbine design was very good since the relative error is only $0.4 \%$ at the design operating conditions. Torque value from mesh (M7) resulted in $78.8 \%$ of model runner efficiency for PCD = $500 \mathrm{~mm}$ (baseline design). The postprocessing visualization (Figures 10 and 11) was able to qualitatively show that the reason for the better performance for the case of baseline design may be explained by less cutout leakage and a more optimal bucket design for its intended use. As presented in Table 11, the model hydraulic efficiencies for reduced size of the turbine (PCD $=400 \mathrm{~mm}$ ) for mesh (M8) were only $62.6 \%, 66.1 \%$, and $71.64 \%$. It can be observed that, from the results of the different cases analyzed, these hydraulic efficiencies were remarkably lower than that of the baseline

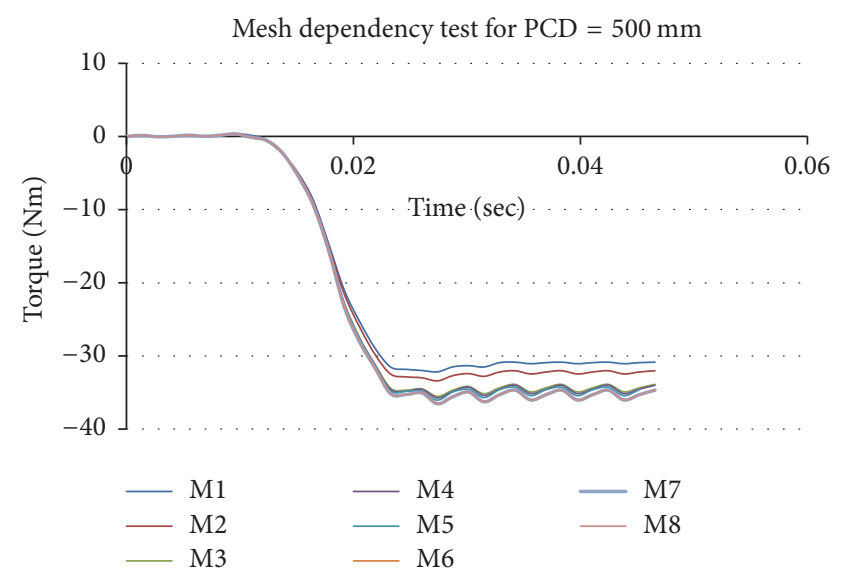

FIGURE 19: Total torque variations for different mesh sizes for PCD $=500 \mathrm{~mm}$.

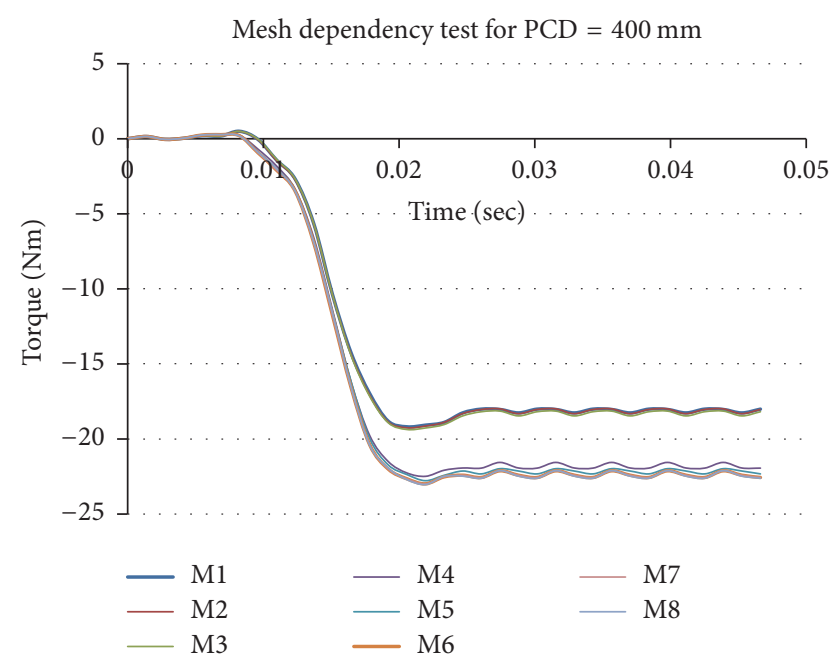

FIGURE 20: Total torque variations for different mesh sizes for PCD $=400 \mathrm{~mm}$.

design. Moreover, it can be observed that for a reduced flow rate and an increase in number of buckets equal to $0.05 \mathrm{~m}^{3} / \mathrm{s}$, 22 , respectively, more water was catched by the inner surface of the buckets. This could explain why the predicted efficiency increases rapidly for volume flow less than the design flow 
rate. The lower efficiency of the model at off-design condition $(\mathrm{PCD}=400 \mathrm{~mm})$ is mainly due to a little backsplash (the breaking effect) on the bucket and the missing jet velocity (leakage flow rate) because of a nonoptimized bucket design. As this phenomenon highlighted before, the qualitative views of Figures 13-15 are reasonable for the lower efficiencies in the off-design cases. Thus, the goal was to compare flow visualization at these two conditions, using image postprocessing, in order to explain the difference in runner performance. An explanation for the discrepancy is that a decrease in PCD from the baseline design $(\mathrm{PCD}=500 \mathrm{~mm})$ to $\mathrm{PCD}=400 \mathrm{~mm}$ would lead to high hydraulic losses, even though it will result in less value of manufacturing cost. It is important to note that the bucket shape used in the baseline design (as shown in Figure 4) in this paper is based on Jeremy Thake 2000 book [6]. In this book, it is suggested that "the design jet diameter is $11 \%$ of PCD" which will give a PCD of approximately $500 \mathrm{~mm}$. Therefore, if we optimize/change the shape of this bucket for each case analyzed above, the optimum results presented in both published results above and the reduced size of the turbine ( $\mathrm{PCD}=400 \mathrm{~mm}$ ) might be different from this study. For future work, the design optimization of this turbine bucket will be made by keeping the PCD to be $400 \mathrm{~mm}$, to lower the manufacturing cost and improve efficiency of the runner. CFD results by Židonis and Aggidis [25] also show that less number of buckets were required to increase the hydraulic efficiency. Therefore, as the final step, it was decided to change the length, depth, and angular position (jet-bucket interaction) and alter the surface close to the lip and redefine the shape of the lip curve to reduce the leakage, intern to reduce the energy loss.

\section{Conclusion}

The next-generation turbine designs for small-scale hydropower systems seek higher efficiency and low manufacturing costs. The (size of Pelton turbine) PCD is an important parameter to lower the manufacturing cost of a Pelton turbine runner. However, no consistent guidance based on numerical research data is available in the public domain. This study provides a guideline for selecting, designing, modeling, and performance analysis of a micro hydro Pelton turbine and provides an example of how the size of turbine (PCD) can affect the efficiency of the turbine.

The paper describes also the methods used for CFD analysis of scaled model Pelton turbine which is ideally designed for Melkey Herra Village hydropower plant using ANSYS CFX software. The bucket model was designed according to the baseline design or calculated parameters. The time and cost in CFD analysis of Pelton turbine are also reduced by selecting 3 buckets to predict the flow behavior of complete turbine. One of the objectives was to understand how the turbine performance will change when the flow field is perturbed by reducing the size of turbine for a given operating condition (i.e., flow rate and head). Results obtained from the baseline design $(\mathrm{PCD}=500 \mathrm{~mm}$ ) have been successfully compared to that of the reduced size $(\mathrm{PCD}=400 \mathrm{~mm})$ of the turbine. The results of the two turbine designs at the design flow rate and head of turbine are as follows: one turbine $(\mathrm{PCD}=$
$400 \mathrm{~mm}$ ) has a maximum efficiency of $62.6 \%$ and the baseline design turbine ( $\mathrm{PCD}=500 \mathrm{~mm}$ ) has a maximum efficiency of $78.8 \%$. The flow visualization study of this research provides insights into the reasons for efficiency as well as guidance for improving the efficiency. The low efficiency in the reduced size of the turbine is mainly caused by a large amount of water leaving the bucket through the lip and hence transferring close to zero of its energy to the shaft. The problem was therefore the choice of the runner PCD that could give the best advantages in terms of efficiency on the whole plant's operational field. For the purpose of validation and performance characterization, two Pelton turbines reported in the literature were considered. The first turbine has PCD = $400 \mathrm{~mm}$, a maximum efficiency of $82.5 \%$, which was studied by Panthee et al., 2014, for Khimti Hydropower in Nepal [10]. The second turbine has also the same PCD (=400 mm) but with a maximum efficiency of $86.7 \%$, which was studied by Panagiotopoulos et al., 2015 [19], using a reference case corresponding to a Pelton turbine installed in the LHT, at the National Technical University of Athens. These were essential for the purpose of computational validation and performance characterization.

The design optimization, production, and experimental testing of a model runner based on this design may also be realized in the next part of this paper. Based on the result obtained, this study planned a modification on the baseline design and will consist of the following new designs being tested:

(i) Changing the length, depth, angular position (Jetbucket interaction), and number of the buckets while keeping all other parameters constant

(ii) Altering the surface close to the lip and redefining the shape of the lip curve to reduce the leakage

Based on the results presented in this study, there are opportunities for improving the maximum efficiency as well as reducing manufacturing cost of Pelton turbines, if the design is prescribed using the above criteria, followed by high-fidelity computational simulations. It would then no longer be necessary to start the design and numerical simulation each time from scratch.

A natural extension of this paper would be also to validate the model for other selected sites. Achieving such a goal would be a great step towards improving the understanding of the micro hydro power development and making tools for validating CFD results, so that the benefits of this technology can be brought to rural populations.

\section{Abbreviations}

CFD: Computational fluid dynamics

CFX: CFD code by ANSYS

SST: $\quad$ Shear stress transport

VOF: Volume of fluid

MHP: Micro hydro power

MHT: Micro hydro turbine

MWIE: Ministry of Water, Irrigation and Energy

BEF: Best efficiency point. 


\section{Conflicts of Interest}

The authors declare that they have no conflicts of interest.

\section{Acknowledgments}

This paper was funded by Ministry of Water, Irrigation and Energy. The authors would like to thank Ministry of Water, Irrigation and Energy Office for the fund and for all information and data provided to accomplish the research work.

\section{References}

[1] Energy Situation, https://energypedia.info/wiki/Ethiopia.

[2] A. Dalelo, Rural Electrification in Ethiopia, opportunities and bottlenecks, Addis Ababa University, College of Education.

[3] World Small Hydropower Development Report 2013- The Need for Further Resource Assessments, L. Esser, International Center on Small Hydro Power, Division of Multilateral Development, Hangzhou, Ethiopia.

[4] S. Melessaw, "Ethiopia's Small Hydro Energy Market-GiZ-target market analysis-hydro ethiopia," http://www.german-energysolutions.de/enwww.gtz.de/projektentwicklungsprogram.

[5] L. F. Barstad, CFD Analysis of a Pelton Turbine [Master, thesis], Norwegian University of Science and Technology, 2012.

[6] J. Thake, The Micro-Hydro Pelton Turbine Manual: Design, Manufacture and Installation for Small-Scale Hydro-Power, ITDG publishing, London, UK, 2000.

[7] Z. Zhang, Pelton turbines book, published by Springer Nature, the registered company is Springer International Publishing, AG, Switzerland, 2016.

[8] MHPG, Series, "Harnessing Water Power on a Small Scale" Vol. 9 (Micro Pelton Turbines), Published by SKAT, Swiss Center for Appropriate Technology, 1991.

[9] A. Harvey, Micro hydro design manual, a guide to small scale water power schemes.

[10] A. Panthee, B. Thapa, and H. P. Neopane, "CFD Analysis of pelton runner," International Journal of Scientific and Research Publications (IJSRP), vol. 4, no. 8, 2014.

[11] A. Zidonis, A. Panagiotopoulos, G. A. Aggidis, J. S. Anagnostopoulos, and D. E. Papantonis, "Parametric optimisation of two Pelton turbine runner designs using CFD," Journal of Hydrodynamics, vol. 27, no. 3, pp. 840-847, 2015.

[12] J. D. Anderson, Computational Fluid Dynamics: The Basics with Applications, McGraw-Hill, New York, NY, USA, 1995.

[13] A. Perrig, Hydrodynamics of the free surface low in Pelton turbine buckets [Ph. D. Thesis], École polytechnique féd, 2007.

[14] A. Perrig, F. Avellan, J.-L. Kueny, M. Farhat, and E. Parkinson, "Flow in a Pelton turbine bucket: numerical and experimental investigations," Journal of Fluids Engineering, vol. 128, no. 2, pp. 350-358, 2006.

[15] Y. X. Xiao, T. Cui, Z. W. Wang, and Z. G. Yan, "Numerical simulation of unsteady free surface flow and dynamic performance for a Pelton turbine," in Proceedings of the 26th IAHR Symposium on Hydraulic Machinery and Systems, chn, August 2012.

[16] M. Eisenring, Micro Pelton turbines. St. Gallen, Switzerland: Swiss Center for Appropriate Technology, 1991.

[17] B. Janetzky, H. Ruprecht, C. Keck, C. Schärer, and E. A. Göde, "Numerical simulation of the flow in a Pelton bucket," in Proceedings of the in. IAHR, pp. 276-283, 1998.
[18] J. S. Anagnostopoulos and D. E. Papantonis, "A fast Lagrangian simulation method for flow analysis and runner design in Pelton turbines," Journal of Hydrodynamics B, vol. 24, no. 6, pp. 930-941, 2012.

[19] A. Panagiotopoulos, A. Židonis, G. A. Aggidis, J. S. Anagnostopoulos, and D. E. Papantonis, "Flow Modeling in Pelton Turbines by an Accurate Eulerian and a Fast Lagrangian Evaluation Method," International Journal of Rotating Machinery, vol. 2015, Article ID 679576, 2015.

[20] B. W. Solemslie and O. G. Dahlhaug, "A reference Pelton turbine design," in Proceedings of the IAHR, 26thIAHR Symposium on Hydraulic Machinery and Systems, IOP Conf., Earth and Environmental Science, Beijing, China, August 2012.

[21] S. Pudasaini, H. P. Neopane, Amod P. et al., "Computational Fluid Dynamics (CFD) analysis of Pelton runner of Khimti Hydro-power Project of Nepal," in Rentech Symposium Compendium, vol. 4, September 2014.

[22] N. Tilahun, W. Bogale, F. Bekele, and E. Dribssa, "Feasibility study for power generation using off- grid energy system from micro hydro-PV-diesel generator-battery for rural area of Ethiopia: The case of Melkey Hera village, Western Ethiopia," AIMS Energy, vol. 5, no. 4, pp. 667-690, 2017.

[23] Hydraulic Turbines, Storage pumps and pump turbines- Model acceptance tests (IEC 60193), 1999.

[24] F. M. White and I. Coreld, Viscous Fluid Flow, vol. 3, McGrawHill, New York, NY, USA, 2006.

[25] A. Židonis and G. A. Aggidis, "Pelton turbine: Identifying the optimum number of buckets using CFD," Journal of Hydrodynamics, vol. 28, no. 1, pp. 75-83, 2016. 


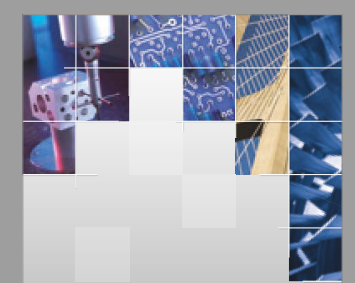

\section{Enfincering}
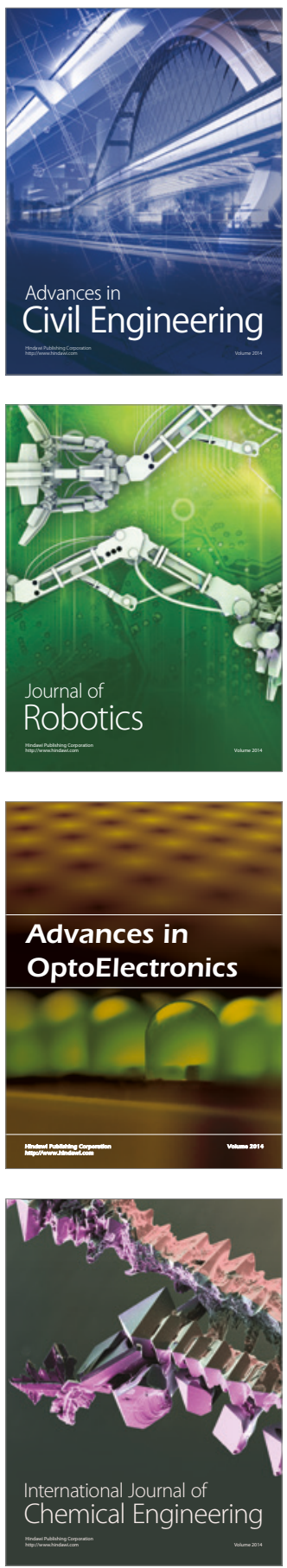

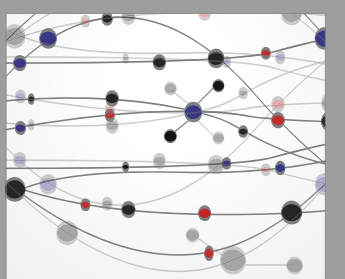

The Scientific World Journal

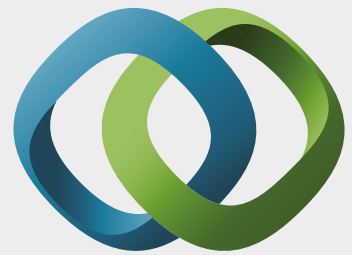

\section{Hindawi}

Submit your manuscripts at

https://www.hindawi.com
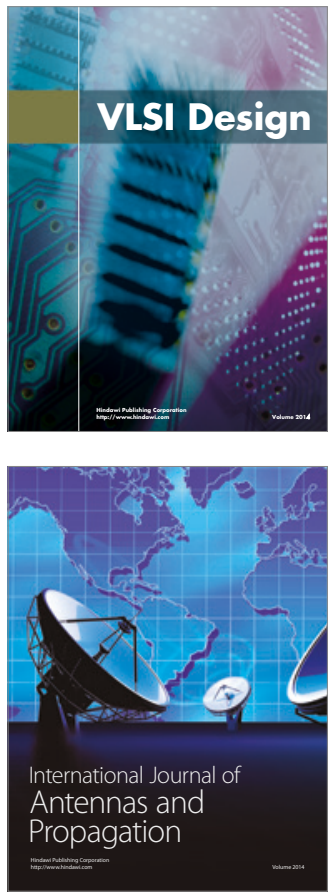

\section{Rotating}

Machinery
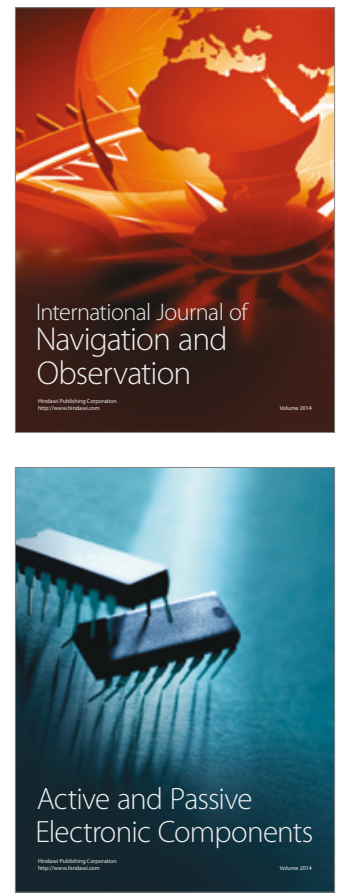
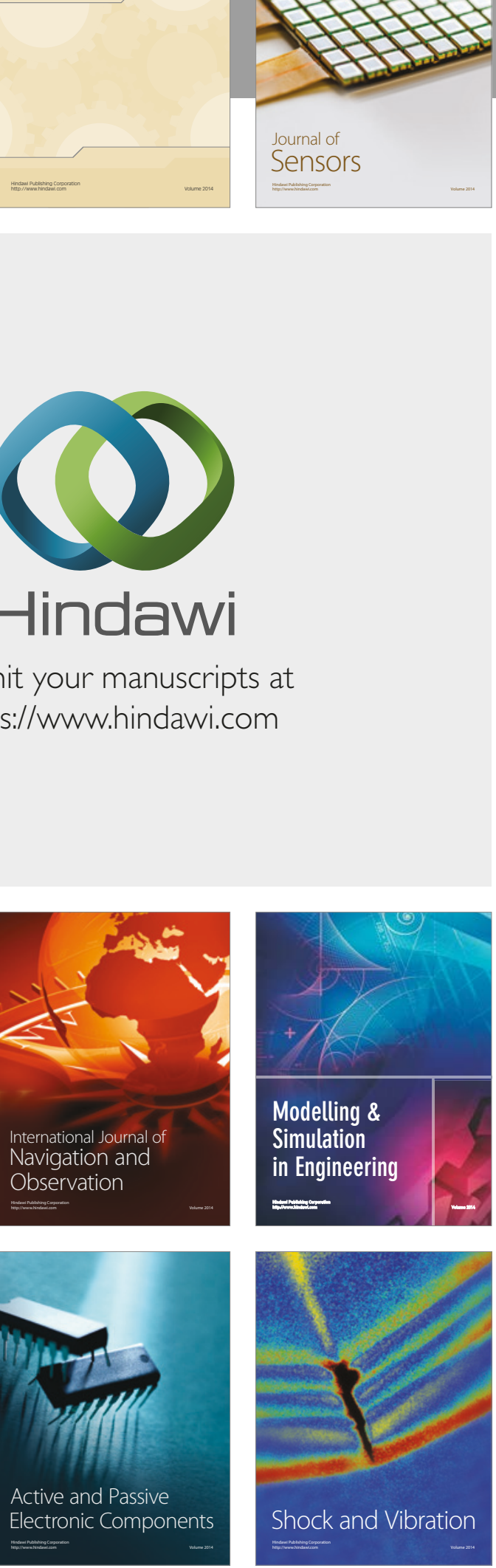
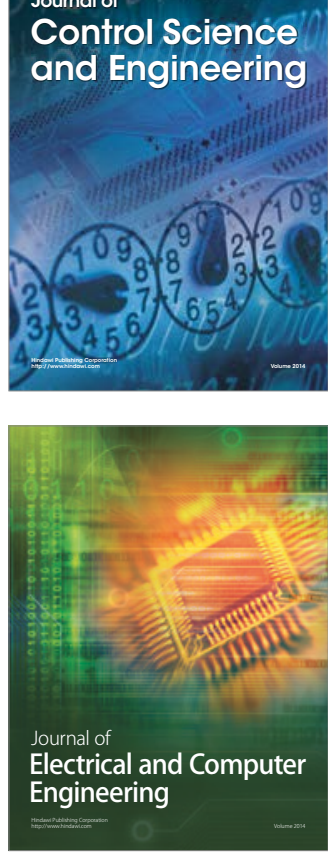

Distributed

Journal of

Control Science

and Engineering
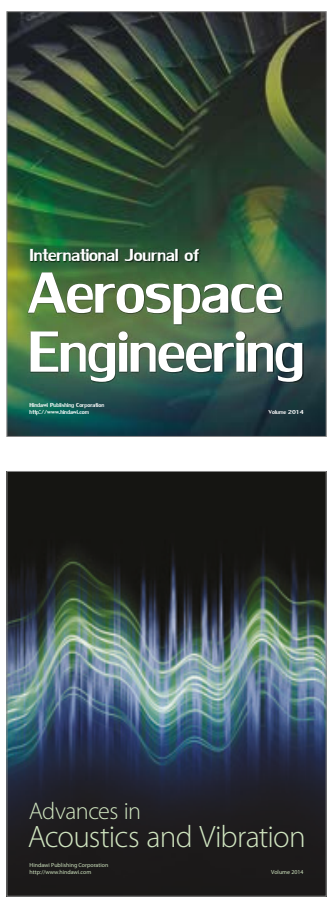

Sensor Networks 